\title{
Blood Cell Dynamics: Half of a Century of Modelling
}

\author{
L. Pujo-Menjouet * \\ Université de Lyon, Université Lyon1, CNRS UMR 5208 Institut Camille Jordan F - 69200 \\ Villeurbanne Cedex, France \\ Inria team Dracula, Inria center Grenoble Rhone-Alpes, 66 Boulevard Niels Bohr,-69603, France
}

\begin{abstract}
The objective of this paper is to give a review of the main works dealing with mathematical modeling of blood cell formation, disorders and treatments within the past fifty years. From the first models to the most recent ones, this research field has inspired many leading experts in mathematics, biology, physics, physiology and computer sciences. Each contribution was a step further to the understanding of these complex processes. This work summarizes the key ones and tries to show not only the evolution of the interest for this problem but also the different research trends throughout the decades up to the latest models of the past years.
\end{abstract}

Keywords and phrases: mathematical modeling, hematopoiesis, blood cell, delay differential equations, structured partial differential equation

Mathematics Subject Classification: 92D25, 92C37, 37N25, 35L02

\section{Introduction}

The aim of this work is to give an overview of the main mathematical models related to blood formation (also called hematopoiesis), disorders and treatments. Thousands of papers have been investigating this topic in the past half century leading to many progresses in the development of mathematical analysis tools, numerical simulations, strategies to estimate parameters and forecast optimal treatments to specific diseases.

Describing all of them in detail would take at least a whole book and certainly several volumes. Our attempt here is to set up what we consider as key contributions to this field and we apologize in advance for the numerous high quality researchers that we do not mention here. Our selection is purely subjective and based on two different criteria:

1. paper introducing the first models of their kind, like for instance the first equations describing cell cycles,

2. the most interesting and impacting results bringing contribution both to the mathematical and biological communities.

Thanks to the development of new techniques both in biology and mathematics, this topic has constantly been evolving throughout decades and the different step forward in the understanding of com-

${ }^{*}$ Corresponding author. E-mail: pujo@math.univ-lyon1.fr

(C) EDP Sciences, 2016 
plex processes needed scientists to continuously adapt their hypotheses. For instance, some speculative modeling assumptions supposed to be holding in the past, were proven to be wrong by biological new experimental protocols (a famous example is the discovery of the role of erythropoietin (EPO), proven to act on cell apoptosis only in the early 1990's). On the other hand, the knowledge of blood cell formation processes have reached such high levels of complexity that it progressively appeared extremely important and helpful to strengthen the already existing collaborations between leading experts in mathematics, biology, physiology, physics and computer sciences altogether.

This is somehow the story that we try to tell here.

But, before starting our journey through more than fifty years of mathematical modeling, it seems important to briefly remind the basics of hematopoiesis.

\subsection{Hematopoiesis: brief biological background}

As it is well described in any biological textbook (see for instance [157]), hematopoiesis deals with formation and regulation of blood cells in the body. It all starts in the developing embryo. Blood cells of the early stages are located in the yold sacs also called blood islands. They move then to the spleen, liver and lymph nodes. After birth, they are formed only in the bone marrow mostly in vertebra, pelvis and sternum.

We are only interested in postnatal hematopoiesis since it is related to most of the different pathologies, treatments and description in the literature. Prenatal hematopoiesis is left to other reviews. In postnatal ages, blood cells always follow the same pattern:

1. they all originate from the same source known as hematopoietic stem cells (HSC). These cells are able to self-renew. They are quite powerful in the sense that only a few of them can repopulate the whole bone marrow after a bone transplant. We shall show that this property is of great importance in the mathematical modeling of hematological disorders.

It is interesting to point here the fact that even if embryonic stem cells have been suggested to exist in 1908 by Maximov [208] (who was the first one to call them this way), evidence of existence of stem cells in the bone marrow was only proven in 1963 by McCulloch and Till [50]. Fifteen years later, in 1978, HSC were found in the blood of the umbilical cord [229]. And we had to wait until 1997 to get a link between leukemia and hematopoietic stem cells showing the first cases of cancer stem cells [66].

2. From HSC, two main cell lineages appear: myeloid and lymphoid. Cells in the lymphoid lineage will give birth to immune cells such as: T-cells, antibody and memory cells. As proliferation, activation and regulation of these cells are located mostly in the lymphoid organs and not the bone marrow, its description is more adapted to immunology theory than hematopoiesis. This is the reason why we do not want to describe the lymphoid branch further here but only cells in the myeloid lineage.

Immature myeloid cells have three possible fates: either becoming a red blood cell, a platelet or a white blood cell.

3. Each lineage is regulated by several growth stimulating factors, essentially hormones. Each one of the three lineages has one leading hormone: erythropoietin (EPO) for red blood cells (found in 1906 by Carnot and Deflandre [75]), thrombopoietin (TPO) for platelets (discovered in 1958 by Kelemen et al. [165]), and granulocyte colony stimulating factor (G-CSF) for white blood cells (discovered in 1985 by Metcalf [209]). Regulation of production of blood cells is highly complex and considering all the actors of this mechanisms is a real challenge. Thus, control systems need to be considered with extreme care when simplified in the mathematical models.

4. Each cell has its own life: during its cycle a new born cell need to go through different phases called $G_{1}, S, G_{2}, M$ and $G_{0}$. The first four phases describe the proliferating phase while the last one stands for the resting phase. During its life, a cell has three main choices: either die by apoptosis (natural cell death) anytime in its cycle or split into two daughter cells at the end of its proliferating phase. If at least one of the daughter cells can be identical to mother cells we face what is called a self-renewing 
process, and if both daughter cells are different from their mother, we call it differentiation. Selfrenewal is often considered for stem cells or progenitor cells. After division, most of normal blood cells reach the $G_{0}$ phase which is not the case for cancer cells who in general keep dividing without resting.

\subsection{Modeling strategies throughout decades: different trends}

Since hematopoiesis is a highly complex process, different strategies have been elaborated throughout the years to get the most appropriate answers to some specific given problems. The common point to all of them has been to remain as simple as possible in order to focus on mainly one objective, like, for instance red blood cell formation only, or impact of cycle disorders to different pathology such as anemia or leukemia, or optimal therapeutic strategies for specific treatments about blood diseases.

Then, mathematical modeling took different aspects depending on the targeted problem. It could have been deterministic only when a large amount of cells is observed, with or without diffusion depending on whether space or not is considered. There would have been some feedback at different level if necessary. Stochastic processes may have been inserted in the model if the number of cell population was not large enough or if some event could be highly unpredictable. Multiscale modeling could have been chosen when interaction at different levels (molecular, cell, and organ levels for instance) is investigated. Some delays in reactions may have been put in equations when necessary and eventually only numerical simulations have been developed when the models were too complicated to analyze theoretically. Individual based models (IBM) also called agent based models (ABM) and multi-agent systems have then been introduced to handle some of these complex models.

Each decade had followed different modeling trends. Some of them remained highly active throughout several decades while others seemed to have left this field for others.

The main question we shall try to answer in this paper is the following: do mathematical models applied to blood cell formation tend to behave like the cells they try to describe? In other words, do they die by natural death, do they self-renew somehow throughout decades or to they differentiate to more "mature" models?

In order to answer this question, we give the most representative models of each decades and try to see if they were trends only for a couple of years, whether they were rich enough to survive through years, or if they evolved to something more elaborated or at least different.

Each section will be dedicated to one decade, starting with the 1960's. There will be thus 5 sections for 50 years of blood cell dynamics studies. These sections will not be well balanced, in the sense that early years were not as prolific as the last ones. However, we will try to be as synthetic as possible and as fair as possible to depict these half of a century's journey in this incredibly rich research field.

\section{The 1960's: early models}

Up to the early 1960's, many publications had already provided quantitative data about blood cells in the bone marrow (like Hulse [161] for instance). But to the best of our knowledge, no one, at that time had ever proposed a mathematical model to attempt to describe their complex dynamics, until 1963 where the first ones started to emerge [271]. Amongst the earliest papers, the trend seemed to be focused on iron kinetics in the red blood cell population [221]. These models where already quite complex. In [221] for instance, the authors decided to use a compartmental model (see Fig. 1) and distributed delay equations. At that times, mathematical tools to obtain an analytical work out of these equations were not developed yet, and so, only numerical works could be done. Furthermore, although iron oriented only, these models are quite interesting because they already get the spirit of how mathematical models should be built to describe biological phenomena. Let us quote for instance one of the first papers on this field : 
1. "Approximating equations to the experimental data should be as simple as possible. They should not contain a priori terms which are not capable of detection or whose contributions fall within the limits of experimental errors.

2. The approximating equations should lend themselves to interpretations as solutions for the behavior of mathematical models which represent an "idealization" of the metabolic processes considered. These should not contradict the accepted basic concepts of physiology.

3. Such model should elucidate metabolic processes beyond the mere numerical representations of the experimentally available data ,"

taken from the introduction of [271].

These precepts have been followed in almost every point. Indeed, some of the models after this wanted to take some terms that where not possible to measure experimentally but whose existence were at least suggested by experimental evidence.

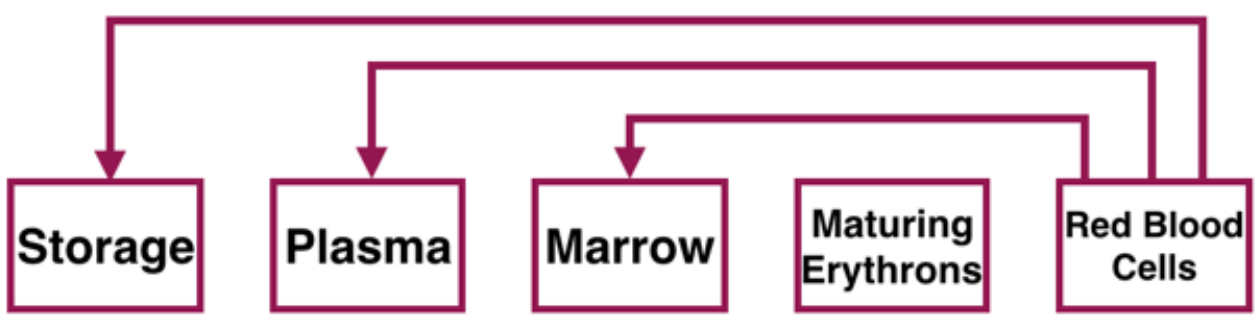

FiguRE 1. "Iron compartmentation and kinetics" from the Nooney model [221].

At the same time a stochastic approach was first introduced in 1963 by Till et al. [282] to describe stem cell proliferation based on the growth of spleen colony forming cells. Even if not focused on the bone marrow, this work was interesting in the sense that it rose some of the most important questions of feedback controls. Moreover, we should point out that this model was built at the exact same time of the discovery of existence of stem cells in the bone marrow [50].

It seems that, in the early 1960's, some scientists started to perceive the importance of the mathematical modeling of blood cell kinetics, to support the most recent biologist's discoveries of that period. We get the feeling that this was the starting point of the development of this branch of mathematics applied to biology, even if, we can express a slight concern about this:most of scientists (if not all of them) developing these models back then, were not mathematician but physicist, chemists, biologists or clinicians. We would have to wait until the end of next decade to notice some first timid steps of mathematicians in this field.

Let us finish the 1960's by the work of Kirk et al. in [167] where oscillation as well as interactions and control mechanisms of the red blood cell and bone marrow stem cell were studied. The mathematical model consisted in four difference-differential equation and studied numerically (see Fig. 2). This paper was the start of a long series of mathematical work developing models to describe periodic oscillating blood diseases.

As seen in this section, the 1960's witnessed the first timid attempts of mathematical models about blood cell dynamics without any contributions of mathematicians. The following decade was about to reveal a clear desire to go further. 


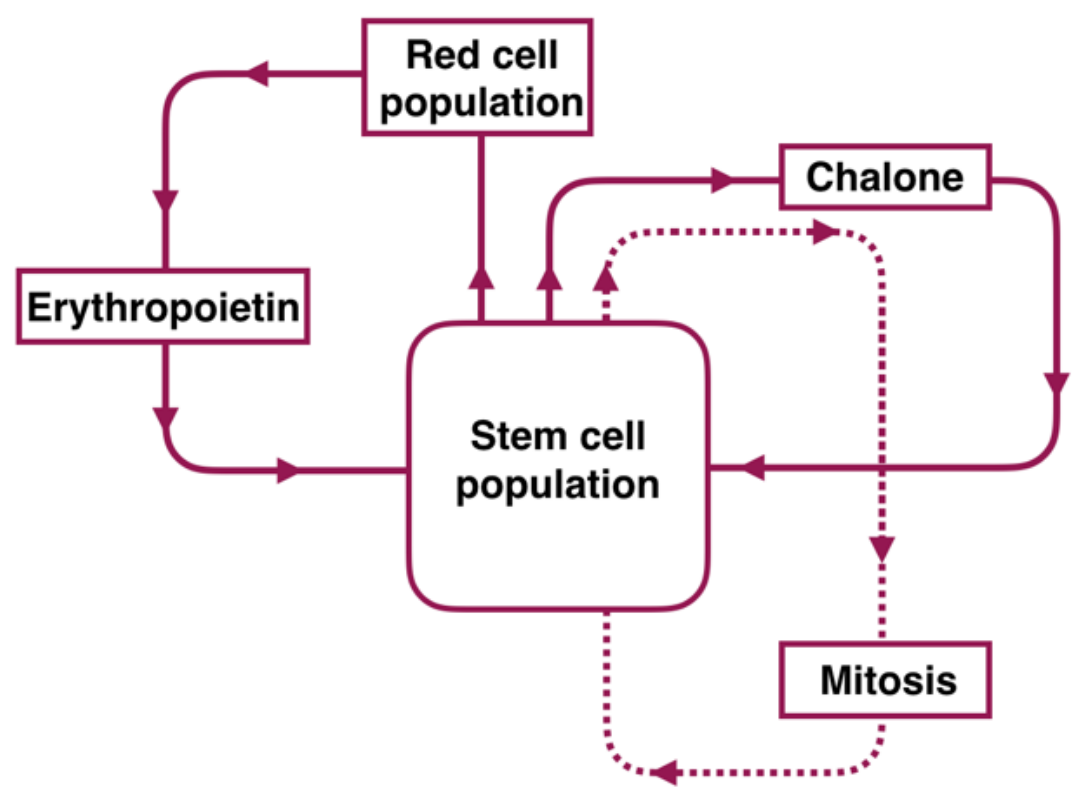

FiguRE 2. Representation of the red and stem cell system from Kirk et al. [167].

\section{The 1970's: the rise of mathematicians' interests}

This decade started quite early in September 1970 when Burns and Tannock [73] proposed for the first time a model of cell cycle including a resting phase also called $G_{0}$ phase. At that time, existence of the $\mathrm{G}_{0}$ phase had recently been admitted. It started indeed with the work of Quastler and Sherman in 1959 [233], the same Quastler, who four years later, in 1963 named, this phase $\mathrm{G}_{0}$ in [232]. This new phase took less than a decade to be well accepted by the biologist community and, thanks to Burns and Tannock, this phase appeared shortly after in a mathematical model (see Fig. 3). Even if this model was not designed for hematopoiesis, but for rat dorsal epidermis cells, it has become the inspiring starting point of a long series of models describing blood cell cycles in the bone marrow. It is interesting to note also that this model included cell labeling (with ${ }^{3} \mathrm{H}$-thymidine in this case) in its equations, and this idea of including cell markers as variables of the model is still currently used. This paper was followed 3 years after by the work of Smith and Martin [273], whose model, even if focused on the dynamics of cells of any kind became also a reference for modelers in hematopoiesis. In this paper, also dealing with ${ }^{3} \mathrm{H}$-thymidine labeling, the authors made a short reference to the Burns and Tannock model "formally identical" to theirs, adding that in 1970, Burns and Tannock "failed to generalize their model, applying it only to slowly proliferating cells. Neither did they adduce firm evidence in its favor, and their paper has not received the attention it deserves, even in the restricted field to which it was applied". We can note that Smith and Martin called the resting phase, the A-state instead of the $\mathrm{G}_{0}$ phase. Moreover, their model consisted in several differential linear equation which was a rather different approach from the Burns and Tannock's work.

It is interesting to make a short remark here: in following decades, to the best of our knowledge, when dealing with cell cycle deterministic models with a resting phase, most of mathematicians were inspired by Burns and Tannock, while biologists and physicists preferred the Smith and Martin one. 


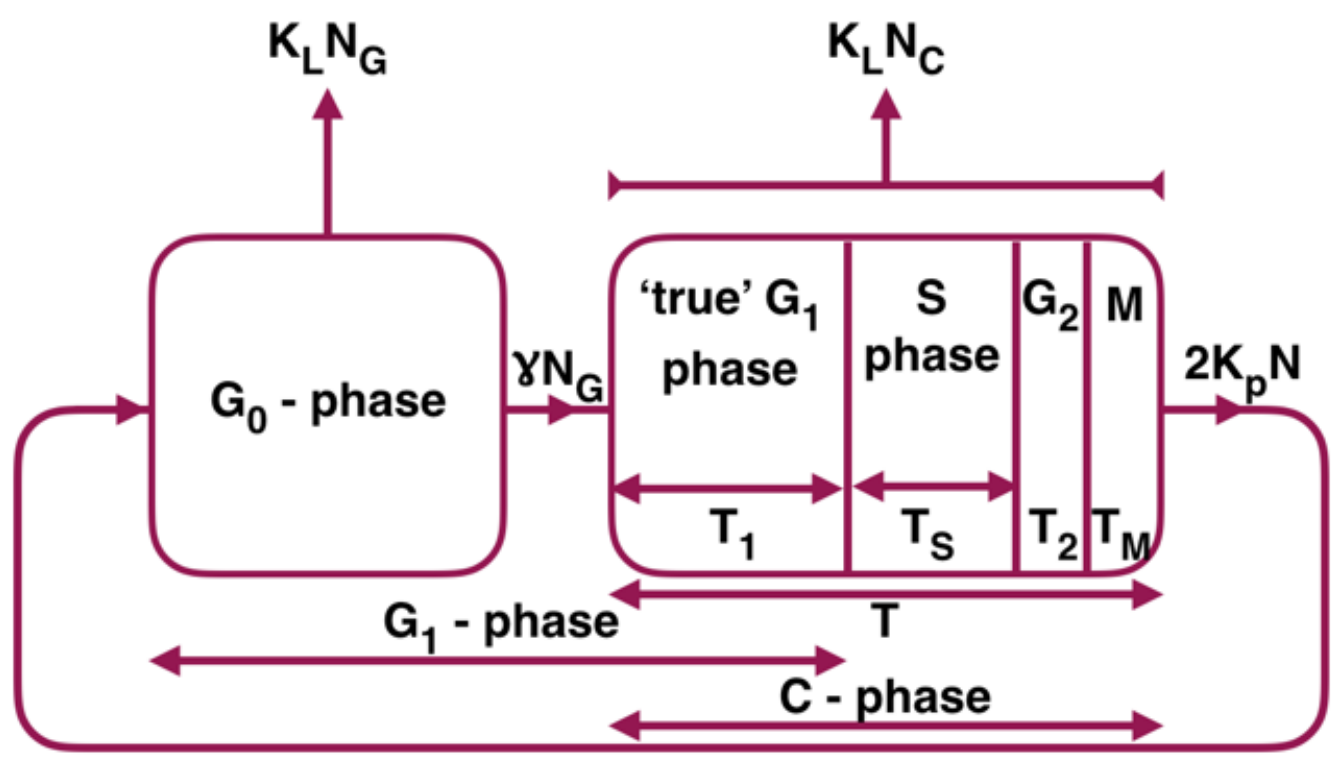

FiguRE 3. Diagram representing the Burns and Tannock $\mathrm{G}_{0}$ model [73].

Let us go back to hematopoiesis. Amongst more than 200 models published in this field during the 1970's (granulopoiesis, control of erythropoiesis, anemia, stem cells, leukemia), several of them caught our attention for different reasons exposed below.

The same year as Burns and Tannock's model, King-Smith and Morley published a work [166] in which they considered the problem of cyclical neutropenia $(\mathrm{CN})$, a blood disease involving a part of the myeloid branch that produces neutrophils. In this work, authors wanted to show that, this disorder was due to a loss of stability in the peripheral control process regulating neutrophil production through a negative feedback between mature neutrophils and their precursors. Based on the Kirk et al. [167] approach, this mathematical model here was more computer oriented, but it was one of the first models dealing with a periodic chronic blood disease with oscillations due to the loss of stability. No mathematical analysis was done in this work but it inspired several authors, like Kazarinoff and van den Driessche in [164], nine years later, and many investigations of chronic blood diseases through Hopf bifurcation would follow in the next decades, becoming one of the modeling trends of that period.

On the same spirit as the Burns-Tannock and Smith-Martin work on trying to describe cell dynamics and estimate parameters with labeling markers, Rubinow and Lebowitz, published a paper in 1975 [253]. The authors introduced the first age-maturity model applied to hematopoiesis (myeloblast cells in this case). They were inspired by the work of Von Foerster [285] who described the kinetics of cellular proliferation with structured partial differential equations but not applied to hematopoiesis. Rubinow and Lebowitz had been working on this problem for more than 6 years before releasing their results about blood cells in the 1975's paper. In 1968, Rubinow, for instance had described a maturity structured model arising from Tetrahymena Gelei human cell cycle. One of the important new feature in this work was the concept of "maturation velocity" [252].

Another turning point during these years were the release of two papers, one in 1976 by Lasota and Ważewska-Czyżewska [175] and the other one in 1977 by Mackey and Glass [198]. Without knowing each other at that time, these authors published almost simultaneously two models very similar in several points: both were arising from red blood cell development (the one from Lasota and Ważewska, see Eq. 
$(3.1))$

$$
\frac{d x(t)}{d t}=-\gamma x(t)+\beta e^{-\alpha x(t-\tau)}
$$

the other, known now as the Mackey-Glass equation, arose from white blood cell production to study a periodic form of chronic myelogenous leukemia (see Eq. (3.2)). Both of them were delay differential equations.

$$
\frac{d x(t)}{d t}=-\gamma x(t)+\beta \frac{x(t-\tau)}{1+x(t-\tau)^{n}} .
$$

Slight changes made the difference: the Lasota -Ważewska model was derived from an age structured partial differential equation, and delay was a consequence of its integration, and on the other hand, the Mackey-Glass equation had been set up directly into a delay differential equation. The non-monotone nature of the nonlinearity of this latter brought a much richer behavior than the derived differential equation. Both approaches remain milestones in the sense that they are still used as references for new mathematical models and the development of delay differential equations. By coincidence WażewskaCzyżewska, Lasota and Mackey met for first time in 1977 just right after having published their work respectively. Another coincidence is that in a third place in the world, another team consisting of Perez, Malta, and Coutinho came out with the same kind of delay differential equation but the model was built to study oscillation of the fly populations [226] (see Eq. 3.3).

$$
\frac{d x(t)}{d t}=-\gamma x(t)+\left(\beta_{0}-\beta_{1} x(t-\tau)\right) x(t-\tau) .
$$

The end of the 1970's was then an important period in the sense that many mathematicians like Rubinow, Mackey, Lasota, van den Driessche and others started to be interested in the modeling of problems arising from hematological issues. And even if they appeared earlier in the 1960's, delay differential equations as well as structured partial differential equations started to be developed and analyzed by mathematicians with the objective to get a better understanding of the hematopoiesis process. It is important to point out that, from the last years of this decade, the study of delay differential equations became a clearly emerging trend. And even at this precise moment where this present paper is written, this trend is still ongoing and it is in great shape.

The 1980's would then surf on this young wave that had started a couple of years before.

\section{The 1980's: mathematicians are in the place}

As mentioned in the introduction, after erythropoietin (EPO) for red blood cells (1906), and thrombopoietin (TPO) for platelets (1958), the last important group of stimulating hormones, involving leukocytes, was discovered in 1985 [209]. It seemed natural then to see this white blood cells stimulating factor, called G-CSF for granulocyte colony stimulating factor, introduced by mathematicians in their models in the second part of this decade (4).

It is interesting to note that, after the 1970's and the rise of mathematician interest in blood cell dynamics, a large number of important hematological discoveries were "fairly" rapidly (less than 10 years) integrated into new mathematical models but not as fast as expected in the beginning (more than five years in average after the first three decades after the 1970's) (see the example of Mackey and Dörmer below for instance). However, this delay has been shortened after the years 2000, as collaboration between mathematicians and biologists became much stronger.

But let us come back to the early 1980's. This period, in the exact continuity of the end of the 1970 's, paved the way to small groups of young mathematicians who showed new modeling perspectives, developed new mathematical tools and had a great impact both in mathematics and biology. 


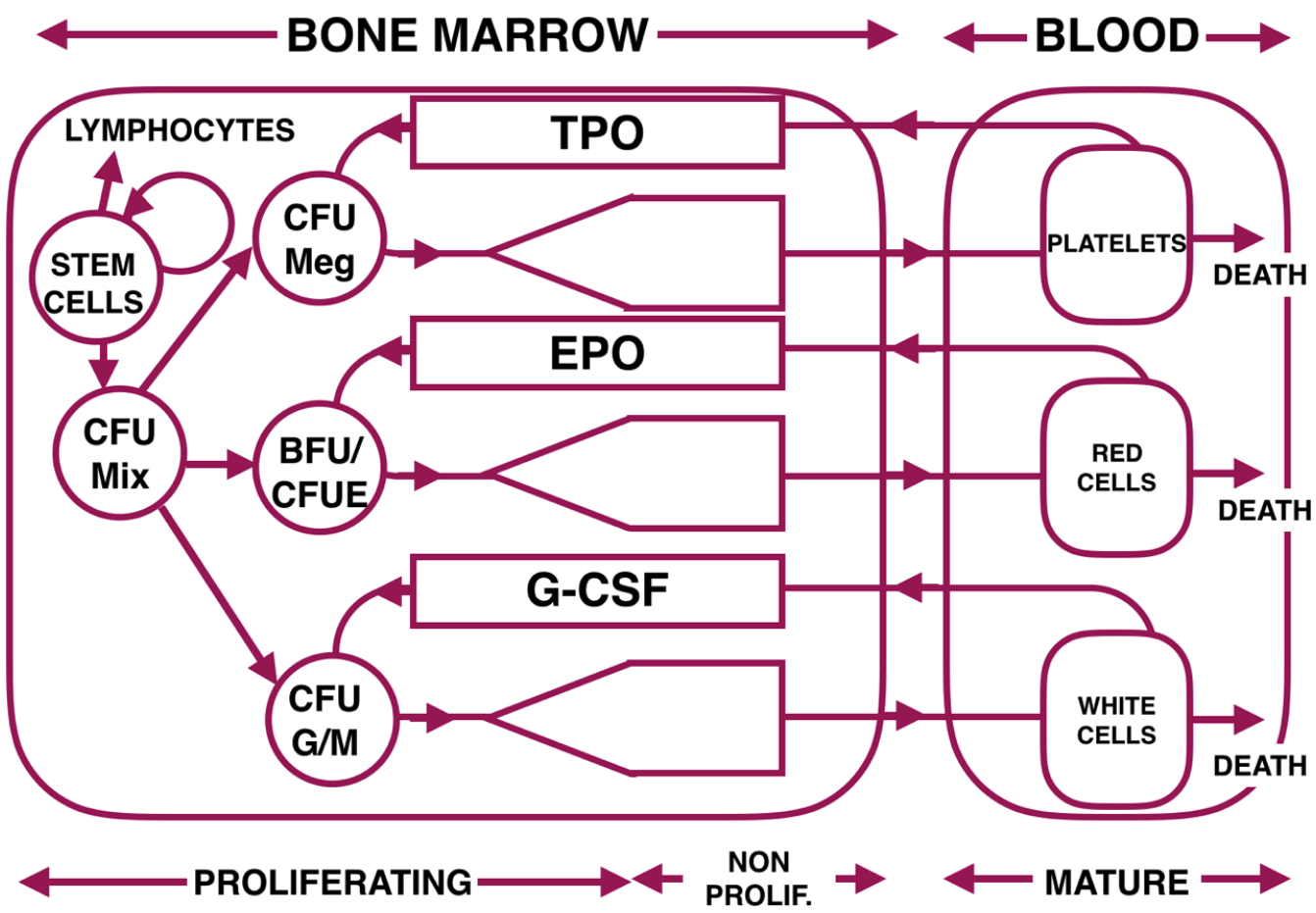

FigURE 4. Illustration of blood regulation system in the bone marrow, with the main stimulating growth factors (EPO, TPO and G-CSF).

In 1980, Lasota and Mackey strengthened their collaboration and investigated mathematically the model of their common interest in [172] with applications to chronic myelogenous leukemia and repeated it in 1981 [173] and in 1984 [174] for the main work applied in hematopoiesis. Mackey developed his work with other collaborators such as Dörmer on erythropoiesis [197], [199] where they studied an age and maturity structured model to be more consistent with experimental data claiming that "proliferating hematopoietic precursor cells may pass between morphological compartments at any point in the cell cycle" and their age-maturity model seemed to be a good approach to describe this mechanism. This work originated from the observation that their available hematopoietic data were inconsistent with some of the previous theoretical work achieved in the 1970's by Rubinow and Lebowitz [253]. And thus, this "old" model where cells were supposed to differentiate (increase maturation) right after cytokinesis needed to be adapted to this new biological hypothesis.

Mackey's prolific collaboration in hematopoiesis modeling followed with An der Heiden and Milton on dynamical diseases and bifurcations in physiological disorders in general and the so called periodic hematopoiesis in particular [195], [34], [217], investigated more in details in the next decades under the forms of cyclical neutropenia, periodic chronic myelogenous leukemia, and cyclical thrombocytopenia. Problem arising from platelet production was the object of a joint work with Bélair at the end of the decade [53] and has been the starting point of a long collaboration in hematopoiesis modeling.

On the other hand, a young group of mathematicians started to emerge also in this field during these years. With a long list of papers on cell cycle they introduced and explored new techniques to analyze some of the past models but also new ones. While the Mackey group was mostly focused on oscillating dynamics and periodic hematological diseases, this group was mostly concentrated on mathematical analysis of structured models, with different structures such as age [286], size [105], [145], as well as 
a mix ot them like age-size [146], [95] and considering equal or unequal division [144], [39]. Some of these models were coming in direct line from the 1970's models or the early 1980's as presented above. But the objectives of these mathematicians was to set up the rigorous mathematical frameworks of the partial differential equations involved (mostly hyperbolic equations of transport type) defining the most appropriate functional spaces to study solutions. They were mainly focused on existence, uniqueness, positivity of the problems as well as stability analysis and asynchronous exponential growth (that is the asymptotically exponential growth of a population with a steady distribution with respect to the structure variables and irrespective of the initial condition) [287], [143] using different tools such as semigroup theory[288], [210], [37], [38] for instance. More theoretical than experimentally oriented, these works could be adapted to many different cell cycle problems and not only to hematopoiesis. But they set up the bases of many models and techniques used in the next decades to solve blood cell formation problems.

Finally, and to the best of our knowledge a third group specialist started to emerge. Also interested in cell proliferation modeling, this group, mainly composed of Wichmann and Loeffler as a base, started to publish their first work about hematopoietic stem cell proliferation in 1980 [185]. Consisting of a system of delayed differential equations, the model is mostly studied numerically and compared with erythroid progenitors experimental data. Their collaboration continued throughout the decade. After a study on the probability of self-renewal hematopoietic stem cells [295], they came back with a more complex system of differential equations, with no delay, to describe the kinetics of hematopoietic stem cells during and after hypoxia [186]. Still dealing with differential equations, they focused their attention on granulopoiesis [235], [296]. In 1988, they summarized their research work on hematopoiesis in four hypothesis [297]. The next year, they released several works: the first one split into two about the study of hematopoiesis under thiamphenicol treatment [141], [187], and the second into four parts to describe stress erythropoiesis in mice and rats [188], [298], [300] (the fourth part was published in 1990 [225]). Equations of these models were composed of systems of differential equations and based on previous models of the late 1960's, the 1970's and the 1980's from Tarbutt and Blakett 1968, Mylrea and Abbrecht (1971), Aarneas (1978), Mary et al. (1980), Leonard et al. (1980), Pabst et al. (1981, 1985) (full references can be found in [188] for instance).

This third group, consisting of clinicians, biologists and biomathematicians, mostly interested by consistency with experimental data and parameter estimates was closer to the Mackey's group spirit than the mathematician young group. The objective of this latter was more theoretically oriented with challenges in developing new mathematical tools and analysis techniques to investigate partial differential equations. Many other groups studied hematopoiesis problem in different forms (as we mentioned few of them above), but these three groups where certainly the most impacting of the 1980s.

Several themes were highlighted by these groups: cyclical diseases, stem cell study, hematopoiesis under treatment, feedback control due to stimulating hormones for the biologist side, and study of systems of differential equations with or without delays, analytic studies of steady states, stability, oscillating behavior, and partial differential equations of transport type with some study of asynchronous exponential growth, and semi-group analysis.

These groups planted the seeds for the development of this branch of mathematics applied to biology. And this seeding appeared to be quite successful since it grew bigger in the following decades.

\section{The 1990's: continuity}

During the 1990s, the three 1980's groups kept on working on their themes, and some new center of interest started to rise. Let us summarize it in this section. Strong collaborations kept on being fruitful. For instance, Mackey produced several works mostly theoretical with Lasota [176], [177] on stability studies for cell replication, work with Milton [200] on feedbacks and delays, Bélair and Mahaffy on two delay models [54] and state dependent delay models with moving boundary contitions [204]. New collaborations started on the same spirit as Lasota, mainly with Rudnicki [202], [203] on theoretical study 
of an age-maturity model. New fields were investigated also like chaos of hematopoietic cell population with Crabb et al. [93]. Note that this theme started to be trendy during this period for hematopoiesis modeling since it was also studied by Webb and collaborators from an analytical point of view: through instability of solutions and hypercyclicity [104], [117], [118], [119], [120]. Some review papers about models of hematopoietic cell replication and control were published to set up a state of the art after three decades of work on this field [42], [193], [44], [152].

One of the most trendy work at this period was leukopoiesis (white blood cell formation) and its related pathologies. Many papers from the Mackey's group as well as the Loeffler's group were published in this field. Most of these works were concerned on mathematical modeling of course, but most importantly on comparison between numerical stimulation and experimental data. This makes sense in regards of what has been said in the previous section about biological discoveries included in models. The granulocyte colony stimulating factor (G-CSF) was discovered in 1985 by Metcalf [209], and started to be intensively studied in mathematical models in the 1990's both by Loeffler and his group starting in 1990 [72], theen in the mid 1990's [220], [97], [99], [100], [266] and late 1990's in [239]. Mackey worked on it only in the late 1990's [153], [155]. Two pathologies rose the attention of these two groups: chronic myelogenous leukemia in its periodic form [133] and [283], [192], both in the late 1990's, and cyclic neutropenia, starting in the middle of the 1990's too for Loeffler [265] and late 1990's for Mackey [156]. Other general cyclic hematopoietic diseases were studied [264], some with chemotherapy modeling attempts [270], [163] or treatments [142] and other hematotoxic products [260]. Few works were focused on erythropoiesis, besides some theoretical approaches from Bélair et al. [54], [202], [254], [256] and some attempts to fit experimental data for anemia [189], or erythropoietin (EPO) effect [98], [101].

Let us come back a few moment here to the short example given in the introduction (section 1)) about EPO. Let us point out two things here: first even if the action of EPO on red blood cell apoptosis regulation in the bone marrow had been discovered in 1990 [170], nobody to our knowledge clearly included this discovery in their models during this decade. It would appear only in some of the models of the late 2000's. On the other hand, megacaryopoiesis was not of great interest at that time, and very few models appeared in this field [125].

It is interesting also to note that the big rise of interest from the "young" mathematician group slightly faded out. Nevertheless, there were still few results on asynchronous exponential growth [147], [289], [290], [45] some on semi-group analysis [258], some with existence and uniqueness results [69], slow oscillation evidences [41], models with unequal division and random transition [40] and emergence of a new interest of aging cells with telomere loss [43], [46].

A little bit like a soufflé, interest of mathematicians on this topic started to fade out as their exploring ideas tended to lead them to some other theoretical work, tools and models. The big "hits" of this decade were certainly leukopoiesis analysis, G-CSF stimulating factors and chaos.

However, the years 2000's gave birth to the new generations taking over certain research fields from their mentors, and new increase of interest rose at the dawn of the new coming century. New biological discoveries, new techniques to obtain experimental data and new collaborations between generations of scientist were about to give new ways of tackling these problems.

\section{The 2000's: from one generation to another}

The years 2000's witnessed the rise of the second generation of mathematicians involved in bone marrow blood cells modeling. Some works followed the guided path of the first generation while new ideas, new themes and new tools started to be explored.

For the models and theory initiated in the previous decades, it was interesting to notice that asymptotic exponential growth applied to blood problems was not trendy any more, and to the best of our knowledge no work was developed besides [123]. Quite popular in the 1980's, this property may come back on the foreground in the next decades for new hematological equations. 
Theoretical evidence of chaos also, a notion that was believed to be promising in the past decade never really took off besides some rare publications on with hypercyclicity in particular [122] and chaos applied to cell cycle in general [124], [255]. Some mathematical tools were developed through theoretical work on the model, specially to study locally or globally asymptotic solutions [9], [10], [22], [87], [12] and bifurcation analysis (mostly Hopf bifurcation leading to oscillation of cell population) [92], [58] [280], [85] for structured partial differential equations (mostly age-structured, but also maturity or age and maturity, or age and cyclin structured...)[79], [51], [51], [121], [29], and differential equations with delays (sometimes discrete, or distributed or state dependent) [56] [30], [31] or impulsions [169].

The main goal for these models was essentially the mathematical development of theoretical tools to develop the problems. They were, for a majority, not quantitatively applied to the biological problems, but qualitatively oriented.

Most of the models were issued from the past decades and slightly generalized for a technical mathematical development.

New approaches started to emerge and developed with a huge technical progress in computer abilities: agent based models or individual based models or multi-agent models [248], [268], [63], [65], [135], [109]. Consisting of a mix of deterministic equations and stochasticity and a lot of computer programming, these new models were aimed at describing either a cell motion, its interactions with the inner and outer cellular environment, or interactions of a group of cells in the bone marrow. They were not totally new from a theoretical point of view, but their applications to hematopoiesis started to rise a great interest from the biological and clinical community. It was possible for once to see almost on live, in silico cells moving and interacting on a motion picture. This novelty managed to illustrate the complex equations used by mathematicians in order to point out the biologist issues and work in a closer cooperation. This field became an excellent way to initiate or to strengthen collaboration between each disciplines, which was and still is one of the most difficult challenges in this area.

The main difficulty for this approach is more technical than theoretical. Once models are set up with biologist and clinician advise, the computer needs to compute tenth, hundreds or thousands cells interacting with each other, getting informations from their environment, dealing with these informations by intra cellular reactions at molecular levels, and providing a decision to communicate to the external environment with other cells: does the cell divide? Does it choose to become a platelet, a red cell, a white cell? And many other decisions. This means hundreds of computations per cell, which leads to a tremendous amount of computations for hundreds of cells interacting. Computers need to be really powerful to handle this. It started to be the case early in the 2000's and keep on being possible with the increase of computer power abilities and decrease of their production price. Development of this branch is then link with the development of technologies, but first results have been really promising.

As mentioned above, this new trend was also coupled with a more frequent introduction of stochasticity in the deterministic models, and specially in the lineage choice, one of the very difficult problems in this decade, and still is in the beginning of the 2010's. Does a cell decide its fate? Does it come from the inside or the outside of the cells, the interactions between other cells or growth hormones influence, or simply a mix of everything creating the medullar environment. If the cell decides its fate, what are the interactions involved. Many attempts consist of tens or hundreds of differential equations. We do not talk about these ones, way too complex to get either an analytic work out of it, but also to investigate the influence of specific parameters. Stochasticity and deterministic approaches were amongst the most appropriate answers to the modeling challenges and started to be popular in the scientific community dealing with lineage choice or cell fate [137], [242], [246], [160].

Let us mention now, two of the largest fields investigated by the modeling community representative of the 2000's trend for blood cell theoretical study were the following. They were not really new, but became real hits in this decade:

1- study of hematopoietic stem cells (HSC),

2- study of blood cancer in general and more particularly leukemia and its treatments. 
Let's start with point 1. Even if assumed early in the 1900's [208], their existence was indirectly confirmed in the beginning of the 1960's [50]. The 1980's and 1990's with the CD34 antigen allowed biologist to target them in a more efficient way and so to be able to get better results in bone marrow transplants. In the late 1990's, 2000's and even now, they are still the object of many experimental and clinical studies linked to their development, life span, division rate, production rates, population number in the bone marrow, plasticity to use them for the development of other organs, plasticity of progenitor cells, turn over rate, ... All these questions have been the object of hundreds of models and thousands of research papers, and even if their development started (from a modeling point of view), in the 1970's, an explosion of their studies emerged in the 2000's with the first and second generations of theoreticians working in this field. On the other hand, many HSC models were used as part of the models in term of sources of cell production. Some models used HSC as an important part of the blood regulation, specially in abnormal cases such as mutations leading to blood cancer. The main issue in that case is to get as many reliable informations on this very particular cell population. Indeed, since many questions remain open and mechanisms quite unclear, the edge between biological consistency and speculation can be really thin in this topic. Some tried to get an estimate of their average number in the organism [107], [108] predicted to be about 400 for an adult human. Other quantitative stem cell modeling have been studied [250], [237], [194]. Some investigated their plasticity and self-organization in detail [190], [249], [191], [238], [241]. It was also the opportunity to develop new delay models [87], [19], [23] with effect of inducing agents [35] or using stochasticity [180]. An other approach was the use of asymmetric division to keep self-renewing properties with differentiation at the same time [205], [251].

Study of HSC is closely related to our point 2. Indeed, since a link between leukemia and hematopoietic stem cells showing the first cases of cancer stem cells had only been proven in the late 1990's [66], it appeared natural to see a great development of stem cell models in describing blood cancers in general and chronic myelogenous leukemia (CML) in particular. This latter became a great hit during the years 2000's. CML was then studied in a great variety of ways, from general models trying to describe the regulating process of oscillating populations through many different feedback (mostly cause by stimulating growth factors) in differential or structured differential equations, with or without delays [25], [26], [134], [230], [201], [83], [84], [82], [112], [85], [231], [148], [215], [216], [240], [245], [138], [150], [3], [24], [113].

Two very interesting modeling topics related to this problem emerged during this decade:

i. modeling CML treatment with three different therapeutic strategies: the first and more popular was Imatinib [247], [212], [214], [78], [159], the second strategy was to use the G-CSF growth hormone (see introduction section 1)) [131], [132], [272] and the third one, with less scientific production (from a modeling point of view) treatments with irradiations [184].

ii- A new problem rose the interest of modelers resistance to blood cancer treatments in general, with applications to CML [244] but also acute myeloid leukemia (AML). This last one, was described either by the study of transition states from CML to AML [112], [213] or by the AML problem only [183], [228], [168], [17].

Other blood diseases were investigated in this period mostly in continuity of the previous decade such as cyclic neutropenia [279], [154], [196], [56], [129], [80] or granulopoiesis in general [126], [267], [222], [223].

Few important topics were studied but did not manage to become clear trends for the 2000's: they were for instance stressed erythropoiesis [91], [2], [49], [63], [14], [13], [16], [11], megakaryopoiesis [259], [36], cell markers applied to blood cells [61], senescence [206], [116] or rare diseases such as beta-thalassemia [236] to mention few of them.

Three topics however started to announce a new point of interest for the years early 2010's: first the implication of circadian rhythm [60], [77] and specially for cancer therapy [179], then techniques to estimate parameter sensitivity [55], [2] and finally the study of cell molecular content [110], also quite well investigated in the development of agent based models and cell fate studies.

Started in the 1990's, this decade offered the opportunity give us a state of the art through several review papers. Each review gave a good insight for different topics: dynamics of hematological diseases [131], 
population models structured by age and size [293], [292] as well as normal and pathological hematopoiesis in general [6].

\section{2010's: a third generation on its way}

It is a little bit early to get an insight of the 2010's. Most of the published works of the beginning of this decade are in the continuity of the end of the 2000's: cyclical neutropenia treatment by G-CSF [181], [182], [71], [94], [301], CML study [139], [158], [224], [106], [48], [178], [257], AML study [275], [274], [47], granulopoiesis [262], [263], HSC study [234], [207], [277], [33], [276], [281], [218], [5], [18], [136], [74] (with two nice reviews dealing with treatments of hematological diseases [96]), [294], very few on erythropoiesis [90], [261], [68] megakaryopoiesis [269], cell fate analysis [219]. There were mathematical development of structured populations [70], [111], [67], [114] with delay equations [20], [88], [21], [15], [59], [4], [28], [27], [32] (with a nice review paper dealing precisely on that topic [89]) or with asymmetric divisions [149].

It is interesting to point out some new or adapted mathematical techniques used to study differentialdifference new models [103], [7], [8], study spatial models [127] or investigate optimal control [115], [278].

Agent based models kept on being developed [162], [140] with complexity following the powerful improvements of computers (see an illustration of computing powerful options in Fig. 5).

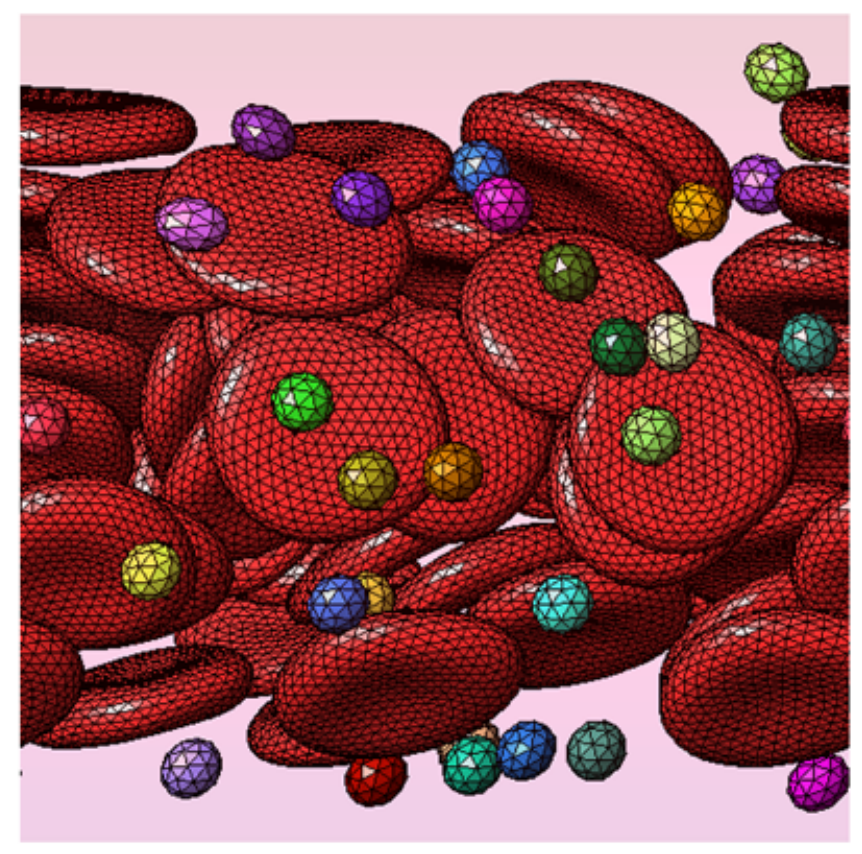

Figure 5. An example red and white blood cell production in 3D [62].

There are actually several important things to note up to now.

1. The interest in modeling hematopoiesis, stem cell dynamics, blood disorders, treatments, resistance to treatment or even blood transplant, never fade out. On the opposite, the seed planted half a century ago became a real strong tree with many strong branches. Some still very young and developed only in the end of the past decade, some a little weak, and others quite furnished. The outcome of this remark is that a great numbers of students are being formed to this problem, and many of them follow interdisciplinary formations, to become not only good in mathematics or biology, but to be experts 
in both of them. The next generation of researchers interested in this field should then appear to be the strong links between the different communities and then propose even better solutions, strategies, tools and techniques to solve problems, design experiments, collect clinical data in order to estimate parameters accurately, propose optimal therapeutic protocols and develop new great models.

2. Numerous modeling attempts, fruitful results and long scientific discussions rose the interest of new mathematicians on this topic (by the development of new analytical and numerical tools) but also curiosity of biologists and clinicians not necessarily incline in exchanging ideas modelers, and more specifically, people dealing with differential and partial differential equations to describe they work. Many scientific success stories of some of these collaboration strengthened the idea that strong interaction between both of these communities was indeed a great idea. It became then easier and almost natural to cooperate on many important clinical issues. One of the most recent examples could be interactions with clinicians and mathematician to develop optimal strategies on the combinations of different treatments at the same time to fight against leukemia, taking into account actions side effects as well as organism circadian clock. Another example could be the study of the problem at different levels (molecular, cellular, inter-cellular, organ) [102], [299] leading to the design of hybrid multi-scale models [64], [128], [171] (see one example in Fig. 6).

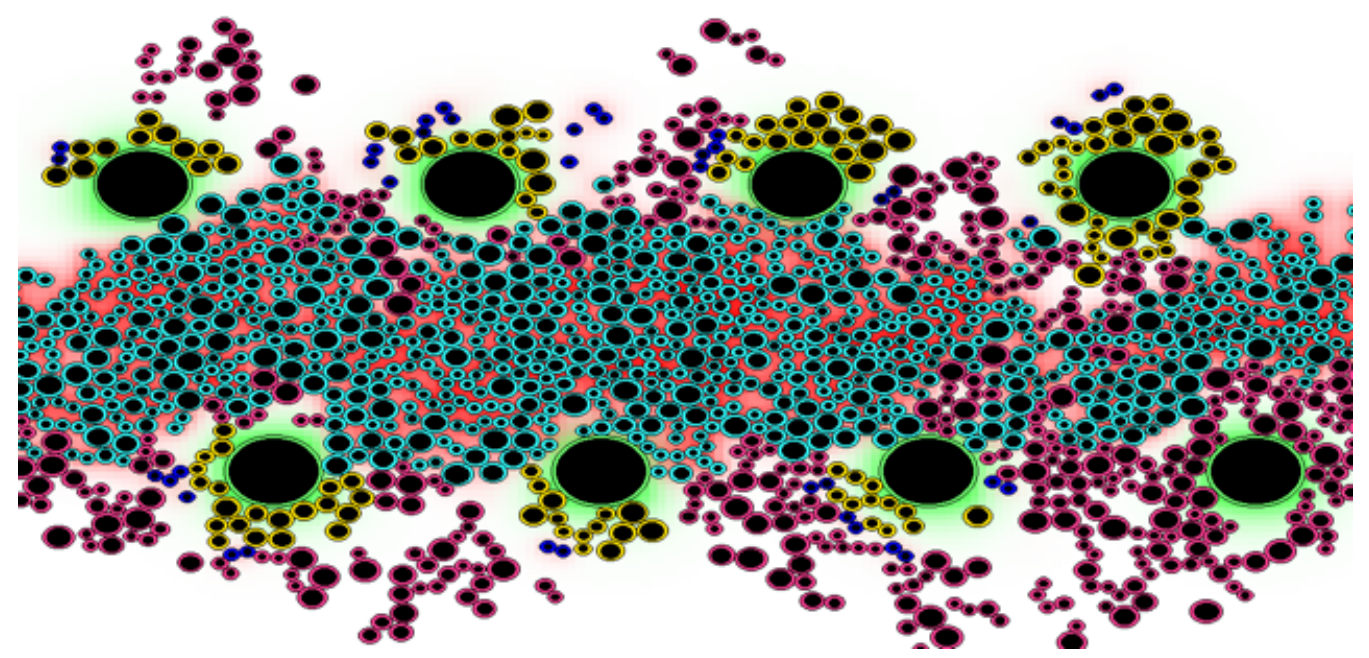

FiguRE 6. The figure shows an example of hybrid modeling of hematopoiesis. Namely, how tumor destroys erythroblastic islands which are the units of red blood cell production in the bone marrow in mammals. Erythroblastic islands are composed of a macrophage (big cells with black center and green annulus around) surrounded by erythroid progenitors (yellow cells) and reticulocytes (blue cells). Macrophages produce growth factors that stimulate self-renewal of erythroid cells (green halo showing the concentration distribution and modeled with PDEs), reticulocytes produce Fas-ligand that determines their differentiation and apoptosis (red halo). Other hematopoietic cells are shown in violet. Tumor cells (light blue) expand and destroy the islands by direct mechanical contact and biochemically by means of Fas-ligand (see [63]-[65], [68], [127], [128], [171] for more details).

Finally one of the most difficult challenges for this decade will be to develop new experimental designs and combine it to new mathematical tools and techniques to estimate sensitivity to several parameters of a model but also to estimate their values in a very accurate way. One of the hot topics of the 2010's is also to get the estimates of parameters for some of the old or new models not only for the average 
population, but to get an individual answer corresponding to each specific profile of a person. This will be then the time for development of "à la carte" treatment following the most accurate and optimal clinical protocols adapted the biological characteristics of every single patient.

Many challenges are thus opening the way to the new generations of interdisciplinary researchers. And the past half century has only been the beginning.

\section{References}

[1] A. S. Ackleh, K. Deng, K. Ito, J. J. Thibodeaux. A structured poiesis model with nonlinear cell maturation velocity and hormone decay rate. Math Biosci. (2006), No. 204 (1), 21-48.

[2] A. S. Ackleh, J. J. Thibodeaux. Parameter estimation in a structured erythropoiesis model. Math Biosci Eng. (2008), No. 5 (4), 601-16.

[3] M. Adimy, O. Angulo, F. Crauste, J.C. Lopez-Marcos. Numerical integration of a mathematical model of hematopoietic stem cell dynamics, Computers Mathematics with Applications. (2008), Vol. 56 (3), 594-60.

[4] M. Adimy, O. Angulo, J. Lopez-Marcos, M. L Opez-Marcos. Asymptotic behaviour of a mathematical model of hematopoietic stem cell dynamics . International Journal of Computer Mathematics. (2014), Vol. 91, No. 2, $198-208$.

[5] M. Adimy, O. Angulo, C. Marquet, L. Sebaa. A mathematical model of multistage hematopoietic cell lineages. Discrete and Continuous Dynamical Systems - Series B (2014) Vol. 19, No. 1, 1-26.

[6] M. Adimy, S. Bernard, J. Clairambault, F. Crauste, S. Génieys, L. Pujo-Menjouet. Modélisation de la dynamique de l'hématopo"ièse normale et pathologique. Hématologie. (2008), 14 (5), 339-350.

[7] M. Adimy, A. Chekroun, T. M. Touaoula. Age structured and delay differential-difference model of hematopoietic stem cell dynamics. Discrete and Continuous Dynamical Systems - Series B. (2015), Vol. 20, No 9, 2765 -2791.

[8] M. Adimy, A. Chekroun,T. M. Touaoula. A delay differential-difference system of hematopoietic stem cell dynamics. Comptes Rendus Mathématiques. (2015), 353 (4), 303-307.

[9] M. Adimy, F. Crauste. Un modèle non-linéaire de prolifération cellulaire : extinction des cellules et invariance. Comptes Rendus Mathématiques. (2003), 336, 559-564.

[10] M. Adimy, F. Crauste. Global stability of a partial differential equation with distributed delay due to cellular replication. Nonlinear Analysis. (2003), TMA, 54 (8), 1469-1491.

[11] M. Adimy, F. Crauste. Stability and instability induced by time delay in an erythropoiesis model. Monografias del Seminario Matematico Garcia de Galdeano. (2004), 31, 3-12.

[12] M. Adimy, F. Crauste. Existence, positivity and stability for a nonlinear model of cellular proliferation. Nonlinear Analysis: Real World Applications. (2005), 6 (2), 337-366.

[13] M. Adimy, F. Crauste. Modelling and asymptotic stability of a growth factor-dependent stem cells dynamics model with distributed delay. Discrete and Continuous Dynamical Systems Series B. (2007), 8(1), 19-38.

[14] M. Adimy, F. Crauste. Mathematical model of hematopoiesis dynamics with growth factor-dependent apoptosis and proliferation regulation. Mathematical and Computer Modelling. (2009), 49, 2128-2137.

[15] M. Adimy, F. Crauste. Delay Differential Equations and Autonomous Oscillations in Hematopoietic Stem Cell Dynamics Modeling. Mathematical Modelling of Natural Phenomena (2012) 7 (6), 1-22. article

[16] M. Adimy, F. Crauste, A. El Abdllaoui. Asymptotic behavior of a discrete maturity structured system of hematopoietic stem cell dynamics with several delays. Journal of Mathematical Modelling and Natural Phenomena (2006), 1(2), 1-19.

[17] M. Adimy, F. Crauste, A. El Abdllaoui. Discrete maturity-structured model of cell differentiation with applications to acute myelogenous leukemia. Journal of Biological Systems (2008), Vol. 16 (3), 395-424

[18] M. Adimy, F. Crauste, A. El Abdllaoui. Boundedness and Lyapunov Function for a Nonlinear System of Hematopoietic Stem Cell Dynamics. Comptes Rendus Mathematique, (2010) 348 (7-8), 373-377.

[19] M. Adimy, F. Crauste, A. Halanay, M. Neamtu, D. Opris. Stability of limit cycles in a pluripotent stem cell dynamics model. Chaos, Solitons and Fractals (2006), 27 (4), 1091-1107.

[20] M. Adimy, F. Crauste, My L. Hbid, R. Qesmi. Stability and Hopf bifurcation for a cell population model with statedependent delay. SIAM J. Appl. Math. (2010) 70 (5), 1611-1633.

[21] M. Adimy, F. Crauste, C. Marquet. Asymptotic behavior and stability switch for a mature-immature model of cell differentiation. Nonlinear Analysis: Real World Applications (2010) 11 (4), 2913-2929.

[22] M. Adimy, F. Crauste, L. Pujo-Menjouet. On the stability of a maturity structured model of cellular proliferation. Dis. Cont. Dyn. Sys. Ser. A (2005), 12 (3), 501-522. .

[23] M. Adimy, F. Crauste, S. Ruan. Stability and Hopf bifurcation in a mathematical model of pluripotent stem cell dynamics. Nonlinear Analysis: Real World Applications (2005), 6 (4), 651-670.

[24] M. Adimy, F. Crauste, S. Ruan. A mathematical study of the hematopoiesis process with applications to chronic myelogenous leukemia. SIAM J. Appl. Math. (2005), 65 (4), 1328-1352.

[25] M. Adimy, F. Crauste, S. Ruan. Periodic Oscillations in Leukopoiesis Models with Two Delays. Journal of Theoretical Biology (2006), 242, 288-299.

[26] M. Adimy, F. Crauste, S. Ruan. Modelling hematopoiesis mediated by growth factors with applications to periodic hematological diseases. Bulletin of Mathematical Biology (2006), 68 (8), 2321-2351.

[27] M. Adimy, K. Ezzinbi, C. Marquet. Ergodic and weighted pseudo-almost periodic solutions for partial functional differential equations in fading memory spaces. Journal of Applied Mathematics and Computing (2014) 44, No. 1-2, 147-165. 
[28] M. Adimy, C. Marquet. On the stability of hematopoietic model with feedback control. C. R. Math. Acad. Sci. Paris. (2012) 350, 173-176.

[29] M. Adimy, L. Pujo-Menjouet. A singular transport model describing cellular division. C.R. Acad. Sci. Paris (2001), 332 (12), 1071-1076.

[30] M. Adimy, L. Pujo-Menjouet. A mathematical model describing cellular division with a proliferating phase duration depending on the maturity of cells. Electron. J. Diff. Equ. (2003), 107, 1-14.

[31] M. Adimy, L. Pujo-Menjouet. Asymptotic behavior of a singular transport equation modelling cell division. Dis. Cont. Dyn. Sys. Ser. B (2003), 3 (3), 439-456.

[32] E. Afenya, S. Mundle. Hematologic Disorders and Bone Marrow Peripheral Blood Dynamics. Math. Model. Nat. Phenom. (2010) Vol. 5, No. 3, 2010, 15-27 DOI: 10.1051/mmnp/20105302.

[33] T. Alarcon, P. Getto, A. Marciniak-Czochra, M. D. Vivanco. A model for stem cell population dynamics with regulated maturation delay. Disc. Cont. Dyn. Syst. Suppl. (2011), 32-43.

[34] U. an der Heiden, M.C. Mackey. Mixed feedback: A paradigm for regular and irregular oscillations. Temporal Disorder in Human Oscillatory Systems (eds. L. Rensing, U. an der Heiden, and M.C. Mackey), Springer-Verlag, New York, Berlin, Heidelberg 1987, 30-36.

[35] E.S. Antoniou, C. L. Mouser, M. E. Rosar, J. Tadros, E. K. Vassiliou. Hematopoietic stem cell proliferation modeling under the influence of hematopoietic-inducing agent. Shock. (2009) Nov;32(5):471-7. doi: 10.1097/SHK.0b013e3181a1a05f.

[36] R. Apostu, M.C. Mackey. Understanding cyclical thrombocytopenia: A mathematical modeling approach. J. Theor. Biol. (2008), 251, 297-316.

[37] O. Arino, M. Kimmel. Asymptotic analysis of a functional-integral equation related to cell population kinetics, NorthHolland Mathematics Studies, Proceedings of the VIth International Conference on Trends in the Theory and Practice of Non-Linear Analysis (1985), 110:27-32.

[38] O. Arino, M. Kimmel. Stability analysis of models of cell production systems, Math. Modelling, (1986), 7, 9-12.

[39] O. Arino, M. Kimmel. Asymptotic analysis of a cell cycle model based on unequal division, SIAM J. Appl. Math., (1987), 47(1):128-145.

[40] O. Arino, M. Kimmel, M. Zerner. Analysis of a cell population model with unequal division and random transition, Lecture Notes in Pure and Appl. Math., 131 (1991), 3-12.

[41] O. Arino, A. Mortabit. Slow oscillations in a model of cell population dynamics, Lecture Notes in Pure and Appl. Math., 131 (1991), 13-25.

[42] O. Arino, M. Kimmel. Comparison of approaches to modeling of cell population dynamics, SIAM J. Appl. Math., 53 (1993) (5):1480-1504.

[43] O. Arino, M. Kimmel, G. F. Webb. Mathematical modelling of the loss of telomere sequences, J. Theoretical Biology, 177 (1995), 45-57.

[44] O. Arino, E. Sánchez. A survey of cell population dynamics, J. Theor. Med., 1 (1997)(1):35-51.

[45] O. Arino, E. Sánchez, G. F. Webb. Necessary and sufficient conditions for asynchronous exponential growth in age structured cell populations with quiescence, J. Math. Anal. Appl., 215 (1997), (2):499-513.

[46] O. Arino, E. Sánchez, G. F. Webb. Polynomial growth dynamics of telomere loss in a heterogeneous cell population, Dynam. Contin. Discrete Impuls. Systems, Arino, O., Axelrod, D. and Kimmel, M., editors. , 3(1997) (3):263-282.

[47] J.L. Avila Alonso, C. Bonnet, J. Clairambault, H. Özbay, S.-I. Niculescu, F. Merhi, A. Ballesta, R. P. Tang, J. P. Marie. Delay Systems : From Theory to Numerics and Applications, T. Vyhlídal, J.-F. Lafay, R. Sipahi eds., Advances in Delays and Dynamics series, Springer, New York (2014), 315-328. Analysis of a New Model of Cell Population Dynamics in Acute Myeloid Leukemia

[48] S. Balea, A. Halanay, D. Jardan, M. Neamţu, C. A. Safta. Stability Analysis of a Feedback Model for the Action of the Immune System in Leukemia. Math. Model. Nat. Phenom. (2014) Vol. 9, No. 1, 108-32 DOI: 10.1051/mmnp/20149108.

[49] H. T. Banks, C. E. Cole, P. M. Schlosser, H. T. Tran. Modeling and optimal regulation of erythropoiesis subject to benzene intoxication. Math Biosci Eng. (2004) Jun;1(1):15-48.

[50] A. J. Becker, E. A. McCulloch, J. E. Till. Cytological demonstration of the clonal nature of spleen colonies derived from transplanted mouse marrow cells. Nature, (1963), 197(4866), $452-4$. (Bibcode:1963Natur.197.452B. doi:10.1038/197452a0)

[51] F. Bekkal Brikci, J. Clairambault, B. Ribba, B. Perthame. An age-and-cyclin-structured cell population model for healthy and tumoral tissues, Journal of Mathematical Biology (2008) 57(1):91-110.

[52] F. Bekkal Brikci, J. Clairambault, B. Ribba, B. Perthame. Analysis of a molecular structured population model with polynomial growth for the cell cycle.Mathematical and Computer Modelling (2008), 47(7-8): 699-713.

[53] J. Bélair, M.C. Mackey. A model for the regulation of mammalian platelet production, Ann. N.Y. Acad. Sci. (1987), 504, 280-282.

[54] J. Bélair, M.C. Mackey, J.M. Mahaffy. Age-structured and two delay models for erythropoiesis, Math. Biosci. (1995), $128,317-346$.

[55] J. Bélair, J.M. Mahaffy. Variable maturation velocity and parameter sensitivity in a model of haematopoiesis. IMA J. Math. Appl. Med Biol. (2001) Jun;18(2):193-211.

[56] S. Bernard, J. Bélair, M.C. Mackey. Sufficient conditions for stability of linear differential equations with distributed delay, Discr. Contin. Dyn. Sys. B (2001), 1:233-256.

[57] S. Bernard, J. Bélair, M.C. Mackey. Oscillations in cyclical neutropenia: new evidence based on mathematical modeling, J. Theor. Biol. (2003), 223:283-298. 
[58] S. Bernard, J. Bélair, M.C. Mackey. Bifurcations in a white-blood-cell production model. C. R. Biologies (2004), 327:201210.

[59] S. Bernard, F. Crauste. Optimal linear stability condition for scalar differential equations with distributed delay. Discrete and Continuous Dynamical Systems Series B (2015) 20 (7), 1855-1876.

[60] S. Bernard, D. Gonze, B. Cajavec, H. Herzel, A. Kramer. Synchronization-induced rhythmicity of circadian oscillators in the suprachiasmatic nucleus. PLOS Comput Biol. (2007) 3:e68.

[61] S. Bernard, L. Pujo-Menjouet, M.C. Mackey. Analysis of cell kinetics using a cell division marker: mathematical modeling of experimental data, Biophys. J.(2003), 84:3414-3424.

[62] N. Bessonov, E. Babushkina, S. F. Golovashchenko, A. Tosenberger, F. Ataullakhanov, M. Panteleev, A. Tokarev, V. Volpert. Numerical Modelling of Cell Distribution in Blood Flow. Math. Model. Nat. Phenom., 9 (2014), no. 6, 69-84.

[63] N. Bessonov, F. Crauste, I. Demin, V. Volpert. Dynamics of erythroid progenitors and erythroleukemia. Mathematical Modeling of Natural Phenomena (2009), 4 (3), 210-232.

[64] N. Bessonov, F. Crauste, S. Fischer, P. Kurbatova, V. Volpert. Application of Hybrid Models to Blood Cell Production in the Bone Marrow. Math. Model. Nat. Phenom. (2011) 6 (7), 2-12.

[65] N. Bessonov, L. Pujo-Menjouet, V. Volpert. Cell Modelling of Hematopoiesis. Math. Model. Nat. Phenom. (2006) Vol. 1, No. 2, 81-103.

[66] D. Bonnet, J.E. Dick. Human acute myeloid leukemia is organized as a hierarchy that originates from a primitive hematopoietic cell. Nature Medicine, (1997), 3 (7), 730-737. doi:10.1038/nm0797-730. PMID 9212098.

[67] R. Borges, A. Calsina, S. Cuadrado, O. Diekmann. Delay equation formulation of a cyclin-structured cell population model. Journal of Evolution Equations (2014) 14 (4-5), 841-862.

[68] A. Bouchnita, N. Eymard, M. Koury, V. Volpert. Initiation of erythropoiesis by BFU-E cells. ITM Web of Conferences 4, 01002 (2015) DOI: 10.1051/itmconf/20150401002.

[69] A. Bouzinab, O. Arino. On the existence and uniqueness for an age-dependent population model with nonlinear growth, Facta Univ. Ser. Math. Inform., (1993) (8):55-68.

[70] D. Breda, O. Diekmann,S. Maset, R. Vermiglio. A numerical approach to investigate the stability of equilibria for structured population models. Journal of biological dynamics (2013) 7 (Suppl. 1), 4-20.

[71] G. Brooks, G. Provencher Langlois, J. Lei, M.C. Mackey. Neutrophil dynamics after chemotherapy and G-CSF: The role of pharmacokinetics in shaping the response J. Theor. Biol. (2012), 315, 97-109.

[72] B. Bungart, M. Loeffler, H. Goris, B. Dontje, V. Diehl, W. Nijhof. Differential effects of rekombinant human colony stimulating factor ( $r$ G G-CSF) on stem cells in marrow, spleen and peripheral blood in mice, Br. J. Haematol. 76 (1990) 174-179.

[73] F. J. Burns, J. F. Tannock, On the existence of a $G_{0}$-phase in the cell cycle. Cell Tissue Kinet. (1970), 3:321-334.

[74] C. Calmelet, A. Prokop, J. Mensah, L. J. McCawley, P. S. Crooke. Modeling the Cancer Stem Cell Hypothesis Math. Model. Nat. Phenom. (2010) Vol. 5, No. 3, 40-62 DOI: 10.1051/mmnp/20105304.

[75] P. Carnot, C. Deflandre Sur l'activité hémopöétique du sérum au cours de la régénération du sang. Comptes rendus hebdomadaires des séances de l'Académie des sciences, (1906), 143: 384-432.

[76] V. Chickarmane, T. Enver, C. Peterson. Computational modeling of the hematopoietic erythroid- myeloid switch reveals insights into cooperativity. PLoS Comput. Biol. (2009) 5, doi:10.1371/journal.pcbi.1000268.

[77] J. Clairambault. A Step Toward Optimization of Cancer Therapeutics. Physiologically Based Modeling of Circadian Control on Cell Proliferation. IEEE-EMB Magazine (2008), 27(1):20-24.

[78] J. Clairambault. Modelling physiological and pharmacological control on cell proliferation to optimise cancer treatments. Mathematical Modelling of Natural Phenomena (2009), 4(3) : 12-67.

[79] J. Clairambault, S. Gaubert, T. Lepoutre. Comparison of Perron and Floquet eigenvalues in age structured cell division models. Mathematical Modelling of Natural Phenomena (2009), 4(3) : 183-209.

[80] C. Colijn, D.C. Dale, C. Foley, M.C. Mackey. Observations on the pathophysiology and mechanisms for cyclic neutropenia. Math. Model. Natur. Phenom. (2006), 1(2) , 45-69.

[81] C. Colijn, C. Foley, M.C. Mackey. G-CSF treatment of canine cyclical neutropenia: A comprehensive mathematical model. Exper. Hematol. (2007), 35, 898-907.

[82] C. Colijn, A.C. Fowler, M.C. Mackey. High frequency spikes in long period blood cell oscillations. J. Math. Biol. (2006), $53(4), 499-519$.

[83] C. Colijn, M.C. Mackey. A mathematical model of hematopoiesis: Periodic chronic myelogenous leukemia, part I. J. Theor. Biol. (2005), 237, 117-132.

[84] C. Colijn, M.C. Mackey. A mathematical model of hematopoiesis: Cyclical neutropenia, part II. J. Theor. Biol. (2005), $237,133-146$.

[85] C. Colijn, M.C. Mackey. Bifurcation and bistability in a model of hematopoietic regulation, SIAM J. App. Dynam. Sys. (2007), 6(2), 378â-394.

[86] F. Crauste. Global Asymptotic Stability and Hopf Bifurcation for a Blood Cell Production Model. Mathematical Biosciences and Engineering (2006), 3 (2), 325-346.

[87] F. Crauste. Delay Model of Hematopoietic Stem Cell Dynamics: Asymptotic Stability and Stability Switch. Math. Model. Nat. Phenom. (2009) Vol. 4, No. 2, 28-47.

[88] F. Crauste. Stability and Hopf bifurcation for a first-order linear delay differential equation with distributed delay, in Complex Time Delay Systems (Ed. F. Atay), Springer, 1st edition, (2010) 320 p., ISBN: 978-3-642-02328-6. 
[89] F. Crauste. A review on local asymptotic stability analysis for mathematical models of hematopoietic with delay and delay-dependent coefficients. Annals of the Tiberiu Popoviciu Seminar of functionnal equations, approximation and convexity (2011) 9, 121-143.

[90] F. Crauste, I. Demin, O. Gandrillon, V. Volpert. Mathematical study of feedback control roles and relevance in stress erythropoiesis. Journal of Theoretical Biology, (2010) 263 (3), 303-316.

[91] F. Crauste, L. Pujo-Menjouet, S. GÃ@)nieys, C. Molina, O. Gandrillon. Adding Self-Renewal in Committed Erythroid Progenitors Improves the Biological Relevance of a Mathematical Model of Erythropoiesis. Journal of Theoretical Biology (2008), 250, 322-338.

[92] F. Crauste, M. Adimy. Bifurcation dans un modÃ $\cdots$ le non-linÃ (C)aire de production du sang. Comptes-rendus de la 7ième Rencontre du Non-linéaire, Non-linéaire Publications, Paris (2004), 73-78.

[93] R. Crabb, M.C. Mackey, A. Rey. Propagating fronts, chaos and multistability in a cell replication model, Chaos (1996) $6,477-492$.

[94] M. Craig, A.R. Humphries, F. Nekka, J. Belair, J. Li, M.C. Mackey. Neutrophil dynamics during concurrent chemotherapy and G-CSF administration: Mathematical modelling guides dose optimisation to minimize neutropenia. J. Theor. Biol. (2015), 385, 77-89.

[95] J. M. Cushing. Existence and stability of equilibria in age-structured population dynamics. Math. Biol. (1984), 20, $259-276$.

[96] D.C. Dale, M.C. Mackey. Understanding, treating and avoiding hematological disease: Better medicine through mathematics?. Bulletin of Mathematical Biology (2015), 77, 739-757.

[97] G. De Haan, C. H. Engel, B. Dontje, W. Nijhof, M. Loeffler. Mutual inhibition of murine erythropoiesis and granulopoiesis during combined erythropoietin, granulocyte colony-stimulating factor and stem cell factor adminstration: In vivo interactions and dose response surfaces. Blood 12 Vol 84 (1994) 4157-4163.

[98] G. De Haan, B. Dontje, W. Nijhof, M. Loeffler. Effects of Continuous Stem Cell Factor Administration on Normal and Erythropoietin-Stimulated Murine Hemopoiesis. Experimental Results and Model Analysis, Stem Cells (Dayt) 13 (1995) 65-76

[99] G. De Haan, C. Engel, B. Dontje, M. Loeffler, W. Nijhof. Hematoxicity by prolonged etoposide adminstration to mice can be prevented by simultaneous growth factor therapy, Cancer Research 55 (1995) 324-329.

[100] G. De Haan, B. Dontje, C. Engel, M. Loeffler, W. Nijhof. The kinetics of murine hemopoietic stem cells in vivo in response to prolonged increased mature blood cell production, induced by granulocyte colony-stimulating factor. Blood 86: 8 (1995) 2986-2992.

[101] G. De Haan, B. Dontje, C. Engel, M. Loeffler, W. Nijhof. In vivo effects of interleukin-11 and stem cell factor in combination with erythropoietin in the regulation of erythropoiesis. British Journal of Hematology (1995) 90: 4, $783-790$.

[102] I. Demin, F. Crauste, O. Gandrillon, V. Volpert. A multi-scale model of erythropoiesis. Journal of Biological Dynamics, (2010) 4 (1), 59-70.

[103] P. K. Dhar,A. Mukherjee, D. Majumder. Difference Delay Equation-Based Analytical Model of Hematopoiesis. Automatic Control of Physiological State and Function Vol. 1 (2012), Article ID 235488, 11 pages doi:10.4303/acpsf/235488.

[104] W. Desch, W. Schappacher, G. F. Webb. Hypercyclic and chaotic semigroups of linear operators, Ergodic Theory and Dynamical Systems 17, (1997), 1-27.

[105] O. Diekmann, H. J. A. M. Heijmans, H. R. Thieme. On the stability of the cell size distribution. J. Math. Biol., (1984) 19:227-248.

[106] O. Diekmann, K. Korvasovà. A didactical note on the advantage of using two parameters in Hopf bifurcation studies. Journal of biological dynamics (2013) 7 (Suppl. 1), 21-30.

[107] D. Dingli, A. Traulsen, J. M. Pacheco. Stochastic dynamics of hematopoietic tumor stem cells. Cell Cycle (2007), 6 : 461-6.

[108] D. Dingli, J. M. Pacheco. Ontogenic growth of the haemopoietic stem cell pool in humans. Proc R Sci B (2007), 274 : 2497-501.

[109] M. D’Inverno, R. Saunders. Agent-Based Modelling of Stem Cell Self-organisation in a Niche. In : Lecture Notes in Computer Science. Berlin/Heidelberg : Springer, (volume 3464/2005), 2008.

[110] M. Doumic. Analysis of a Population Model Structured by the Cells Molecular Content. Math. Model. Nat. Phenom. (2007) Vol. 2, No. 3, 121-152.

[111] M. Doumic, A. Marciniak-Czochra, B. Perthame, J.P. Zubelli. A structured population model of cell differentiation . SIAM Journal on Applied Mathematics (2011) 71 (6), 1918-1940.

[112] I. Drobnjak, A.C. Fowler, M.C. Mackey. Oscillations in a maturation model of blood cell production. SIAM J. Appl. Math. (2006), 66(6), 2027-2048.

[113] A. Ducrot, V. Volpert. On a Model of Leukemia Development with a Spatial Cell Distribution. Math. Model. Nat. Phenom. (2007) Vol. 2, No. 3, 2007, pp. 101-120.

[114] A. Ducrot, F. LeFoll, P. Magal, H. Murakawa, J. Pasquier, G. F. Webb. An in vitro cell population dynamics model incorporating cell size, quiescence, and contact inhibition, Math. Mod. Meth. Appl. Sci. Vol.21 (2011), DOI No: 10.1142/S0218202511005404, 871-892.

[115] X. Dupuis. Optimal Control of Leukemic Cell Population Dynamics.' Math. Model. Nat. Phenom. (2014) Vol. 9, No. 1, pp. 4-26 DOI: $10.1051 / \mathrm{mmnp} / 20149102$.

[116] J. Dyson, E. Sanchez, R. Villella-Bressan, G. F. Webb. Stabilization of telomeres in nonlinear models of proliferating cell lines. J Theor Biol. (2007) Feb 7;244(3):400-8. 
[117] J. Dyson, R. Villella-Bressan, G. F. Webb. A singular transport equation modelling a proliferating maturity structured cell population, Canadian Appl. Math. Quart., Vol.4, No.1 (1996), 65-95.

[118] J. Dyson, R. Villella-Bressan, G. F. Webb. Hypercyclicity of a transport equation with delays, J. Nonl. Anal. Theory Meth. Appl., Vol. 29, No. 12 (1997), 1343-1351.

[119] J. Dyson, R. Villella-Bressan, G. F. Webb. A maturity structured model of a population of proliferating and quiescent cells, Archives of Control Sciences, Vol. 9 (XLV) No. 1-2 (1999), 201-225.

[120] J. Dyson, R. Villella-Bressan, G. F. Webb. An age and maturity structured model of cell population dynamics, Mathematical Models in Medical and Health Science, Proceedings of the Conference on Mathematical Models in Medical and Health Sciences, Vanderbilt University Press, (1999), 99-116.

[121] J. Dyson, R. Villella-Bressan, G. F. Webb. A Nonlinear age and maturity structured model of population dynamics. I. Basic Theory. J. Math. Anal. Appl. Vol. 242 (2000), 93-104.

[122] J. Dyson, R. Villella-Bressan, G. F. Webb. A Nonlinear age and maturity structured model of population dynamics. II. Chaos. J. Math. Anal. Appl. Vol. 242 (2000), 255-270.

[123] J. Dyson, R. Villella-Bressan, G. F. Webb. Asynchronous exponential growth in an age structured population of proliferating and quiescent cells. Math. Biosci.,Vol. 177-178 (2002), 73-83.

[124] J. Dyson, R. Villella-Bressan, G. F. Webb. A semilinear transport equation with delays. Int. J. Math. Math. Sci. Vol. 6, No. 32 (2003), 2011-2026.

[125] C. Engel, M. Loeffler, H. Franke, S. T. Schmitz. Endogenous thrombopoietin serum levels during multicycle chemotherapy British Journal of Haematology (1999) 105, 832-838.

[126] C. Engel, M. Scholz, M. Loeffler. A computational model of human granulopoiesis to simulate the hematotoxic effects of multicycle polychemotherapy. BLOOD (2004), 104 (8) 2323-2331.

[127] N. Eymard Â. N. Bessonov O. Gandrillon Â. M. J. Koury V. Volpert. The role of spatial organization of cells in erythropoiesis J Math Biol. (2015) Jan;70(1-2):71-97. doi: 10.1007/s00285-014-0758-y.

[128] S. Fischer, P. Kurbatova, N. Bessonov, O. Gandrillon, V. Volpert, F. Crauste. Modelling erythroblastic islands: using a hybrid model to assess the function of central macrophage. J. Theo. Biol., (2012) 298, 92-106.

[129] C. Foley, S. Bernard, M.C. Mackey. Cost-effective G-CSF therapy strategies for cyclical neutropenia: Mathematical modelling based hypotheses. J. Theor. Biol. (2006), 238:754-763.

[130] C. Foley, M.C. Mackey. Dynamic hematological disease: A review. J. Math. Biol. (2009), 58, 1, $285-322$.

[131] C. Foley, M.C. Mackey. Mathematical model for G-CSF administration after chemotherapy. J. Theor. Biol. (2009), 257, 27-44. DOI:10.1016/j.jtbi.2008.09.043.

[132] J. Foo, M. W. Drummond, B. Clarkson, T. Holyoke, F. Michor. Eradication of chronic myeloid leukemia stem cells: a novel mathematical model predicts no therapeutic benefit of adding G-CSF to imatinib. PLoS Computational Biology (2009) 5, e10000503. (PDF)

[133] P. Fortin M.C. Mackey. Periodic chronic myelogenous leukemia: Spectral analysis of blood cell counts and etiological implications, Br. J. Haematol. (1999), 104, 336-345.

[134] A. Fowler, M.C. Mackey. Relaxation oscillations in a class of delay differential equations. SIAM J. Appl. Math. (2002), 63, 299-323.

[135] J. Galle J, G. Aust, G. Schaller, T. Beyer, D. Drasdo. Individual cell-based models of the spatio-temporal organisation of multicellular systems - achievements and limitations. Cytometry (2006) 69A : 704-10.

[136] P. Getto, A. Marciniak-Czochra. Mathematical Modelling as a Tool to Understand Cell Self-renewal and Differentiation Mammary Stem Cells: Methods and Protocols (2015) 247-266.

[137] I. Glauche, M. Cross, M. Loeffler, I. Roeder. Lineage specification of hematopoietic stem cells: mathematical modeling and biological implications. Stem cells (Dayton, Ohio) 25 (2007), 1791-9.

[138] I. Glauche, M. Horn, I. Roeder. Leukaemia stem cells: hit or miss? British Journal of Cancer 96 (2007), 677-9.

[139] I. Glauche, K. Horn, M. Horn, L. Thielecke, M. A. Essers, A. Trumpp, I. Roeder. Therapy of chronic myeloid leukaemia can benefit from the activation of stem cells: simulation studies of different treatment combinations. British journal of cancer 106 (2012) 1742-52.

[140] I. Glauche, I. Roeder. In silico hematology. Systembiologie.de 42 (2014) 19.

[141] H. Goris, M. Loeffler, B. Bungart, S. Schmitz, W. Nijhof, Hemopoiesis during thiamphenicol treatment. I. Stimulation of stem cells during eradication of intermediate cell stages, Exp. Hematol., 17 (1989), 957-961.

[142] H. Goris, B. Bungart, M. Loeffler, W. Nijhof. Migration of stem cells and progenitors between marrow and spleen following a thiamphenicol treatment of mice, Exp. Hematol. 18 (1990) 400-407.

[143] A. Grabosch, G. F. Webb. Asynchronous exponential growth in transition probability models of the cell cycle, SIAM J. Math. Anal. 18, (1987),No. 4, 897-907.

[144] M. Gyllenberg. The age structure of populations of cells reproducing by asymmetric division, in Mathematics in biology and medicine, V. Capasso, E. Grosso and S.L. Paveri-Fontana (Eds.), Springer Lecture Notes in Biomathematics, (1985), 57, 320-327.

[145] M. Gyllenberg, H. J. A. M. Heijmans. An abstract delay-differential equation modelling size dependent cell growth and division, SIAM J. Math. Anal. (1987),18, 74-88.

[146] M. Gyllenberg, G. F. Webb. Age-size structure in populations with quiescence. Math. Biosci., (1987) 86(1):67-95.

[147] M. Gyllenberg, G. F. Webb. Asynchronous exponential growth of semigroups of nonlinear operators, J. Math. Anal. Appl. 167, No. 2 (1992), 443-467.

[148] H. Haeno, R. L. Levine, D. G. Gilliland, F. Michor. A progenitor cell origin of myeloid malignancies. Proc. Natl. Acad. Sci. U S A (2009) 106, 16616-16621. 
[149] A. Halanay, D. Cândea, I. R. Rădulescu. Existence and Stability of Limit Cycles in a Two-delays Model of Hematopoiesis Including Asymmetric Division. Math. Model. Nat. Phenom. (2014) Vol. 9, No. 1, 58-78 DOI: $10.1051 / \mathrm{mmnp} / 20149105$.

[150] D. Hasenclever, O. Brosteanu, T. Gerike, M. Loeffler. Modelling of chemotherapy: The effective dose approach. Ann. Hematol. (2001), 80: B89-B94.

[151] C. Haurie, D.C. Dale, M.C. Mackey. Cyclical neutropenia and other periodic hematological disorders: A review of mechanisms and mathematical models, Blood (1998), 92, 2629-2640.

[152] C. Haurie, D.C. Dale, M.C. Mackey. Cyclical neutropenia and other periodic hematological disorders: A review of mechanisms and mathematical models, Blood (1998), 92, 2629-2640.

[153] C. Haurie, D.C. Dale, M.C. Mackey. Occurrence of periodic oscillations in the differential blood counts of congenital, idiopathic and cyclical neutropenic patients before and during treatment with G-CSF, Exper. Hematol. (1999), 27, 401-409.

[154] C. Haurie, D.C. Dale, R. Rudnicki, M.C. Mackey. Modeling of complex neutrophil dynamics in the grey collie. J. theor. Biol. (2000), 204, 505-519.

[155] C. Haurie, R. Person, D.C. Dale, M.C. Mackey. Hematopoietic dynamics in grey collies, Exper. Hematol. (1999), 27, 1139-1148.

[156] T. Hearn, C. Haurie, M.C. Mackey. Cyclical neutropenia and the peripheral control of white blood cell production, J. Theor. Biol. (1998), 192, 167-181.

[157] R. Hoffman, E.J. Benz, L.E. Silberstein, H. Heslop, J. Weitz and J. Anastasi. Hematology: Basic Principles and Practice, 6th edition. Churchill Livingstone, Elsevier, 2102.

[158] M. Horn, I. Glauche, M. C. Müller, R. Hehlmann, A. Hochhaus, M. Loeffler, I. Roeder. Model-based decision rules reduce the risk of molecular relapse after cessation of tyrosine kinase inhibitor therapy in chronic myeloid leukemia. Blood 121 (2013) 378-84.

[159] M. Horn, M. Loeffler, I. Roeder. Mathematical modeling of genesis and treatment of chronic myeloid leukemia. Cells, tissues, organs 188 (2008), 236-47.

[160] S. Huang, Y. P. Guo, G. May, T. Enver. Bifurcation dynamics in lineage-commitment in bipotent progenitor cells. Dev. biol. (2007), 305, 695-713.

[161] E. V. Hulse. Recovery of Erythropoiesis after Irradiation: A Quantitative Study in the Rat. Brit. J. Haemat., (1963), $9,365-375$.

[162] A. Krinner, I. Roeder, M. Loeffler, M. Scholz. Merging concepts - coupling an agent-based model of hematopoietic stem cells with an ODE model of granulopoiesis. BMC systems biology 7 (2013) 117.

[163] M. Johnson, G. F. Webb. Resonances in age structured cell population models of periodic chemotherapy, Internat. J. Appl. Sci. Comp., Vol 3, No. 1 (1996), 57-67.

[164] N. D. Kazarinoff, P. van den Driessche, P. Control of oscillations in hematopoiesis, Science (1979),203, 1348-1350.

[165] E. Kelemen, I. Cserhati, B. Tanos. Demonstration and some properties of human thrombopoietin in thrombocythemic sera, Acta Haematol., (1958), 20, 350-355.

[166] E. A. King-Smith, A. Morley. Computer simulation of granulopoiesis: normal and impaired granulopoiesis, Blood (1970), 36, 254-262.

[167] J. Kirk, J. S. Orr, C. S. Hope. A Mathematical Analysis of Red Blood Cell and Bone Marrow Stem Cell Control Mechanisms. British Journal of Haematology, (1968), 15, 1, 35-46.

[168] L. Kold-Andersen, M.C. Mackey. Resonance in periodic chemotherapy: A case study of acute myelogenous leukemia. J. Theor. Biol. (2001), 209, 113-130.

[169] C. Kou, M. Adimy, A. Ducrot. On the dynamics of an impulsive model of hematopoiesis. Journal of Mathematical Modelling and Natural Phenomena (2009) 4(2), 89-112.

[170] M. Koury, M. Bondurant, Erythropoietin retards DNA breakdown and prevents pro- grammed death in erythroid progenitor cells, Science, 248 (1990), pp. 378-381.

[171] P. Kurbatova, S. Bernard, N. Bessonov, F. Crauste, I. Demin, C. Dumontet, S. Fischer, V. Volpert. Hybrid model of erythropoiesis and leukemia treatment with cytosine arabinoside. SIAM J. App. Math. (2011) 71 (6), $2246-2268$.

[172] A. Lasota, M. C. Mackey, The Extinction of Slowly Evolving Dynamical Systems, J. Math. Biology (1980), 10, 333-345

[173] A. Lasota, M.C. Mackey, M. Wazewska-Czyzewska, Minimizing therapeutically induced anemia, J. Math. Biol. (1981) $13,149-158$.

[174] A. Lasota, M.C. Mackey, Globally asymptotic properties of proliferating cell populations, J. Math. Biol. (1984) 19, $43-62$.

[175] A. Lasota, M. Ważewska-Czyżewska, Matematyczne problemy dynamiki uktadu krwinek czerwonych (Mathematical problems of the dynamics of red blood cell population), (in Polish), Matematyka Stosowana (1976), 6:23-40.

[176] A. Lasota, K. Loskot, M.C. Mackey. Stability properties of proliferatively coupled cell replication models, Acta Biotheor., 39 (1991), 1-14.

[177] A. Lasota, M.C. Mackey. Cell division and the stability of cellular replication, J. Math. Biol., 38, (1999), $241-261$.

[178] U. Ledzewicz, H. Schättler. A Review of Optimal Chemotherapy Protocols: From MTD towards Metronomic Therapy. Math. Model. Nat. Phenom. Vol. 9, No. 4, (2014), 131-152 DOI: 10.1051/mmnp/20149409.

[179] F. Lévi, A. Altinok, J. Clairambault, A. Goldbeter. Implications of circadian clocks for the rhythmic delivery of cancer therapeutics. Phil. Trans. Roy. Soc. A (2008), 366 (1880), 3575-3598.

[180] J. Lei, M.C. Mackey. Stochastic differential delay equation, moment stability, and appplication to hematopoietic stem cell regulation system. SIAM J. Appl. Math., 67(2) (2007), 387-407. 
[181] J. Lei, M. C. Mackey. Multistability in an age-structured model of hematopoiesis: Cyclical neutropenia. J. Theor. Biol., 270 (2011), 143-153.

[182] J. Lei, M. C. Mackey. Understanding and treating cytopenia through mathematical modeling in Systems Biology Approach to Blood (ed. S. Corey, M. Kimmel, J. Leonard), Springer-Verlag (2013).

[183] A. Liso, F. Castiglione, A. Cappuccio, F. Stracci, R. F. Schlenk, S. Amadori, C. Thiede, S. Schnittger, P. J. M. Valk, K. Doehner, M. F. Martelli, M. Schaich, J. Krauter, A. Ganser, M. P. Martelli, N. Bolli, B. Loewenberg, T. Haferlach, G. Ehninger, F. Mandelli, H. Doehner, F. Michor, B. Falini. A one-mutation mathematical model can explain the age incidence of AML with mutated nucleophosmin (NPM1). Haematologica, 93 (2008), 1219-1226.

[184] M. Loeffler. Modelling the effects of continuous irradiation on murine haematopoiesis. British Journal of Radiology, (S26) (2002), 188-197.

[185] M. Loeffler, H. E. Wichmann, A comprehensive mathematical model of stem cell proliferation which reproduces most of the published experimental results, Cell Tissue Kinet., 13 (1980), 543-561.

[186] M. Loeffler, P. Herkenrath, H. E. Wichmann, B.I. Lord, M.J. Murphy, The kinetics of hematopoietic stem cells during and after hypoxia - A model analysis, Blood, 49, (1984), 427-439.

[187] M. Loeffler, B. Bungart, H. Goris, S. Schmitz, W. Nijhof, Hemopoiesis during thiamphenicol treatment. II. A theoretical analysis shows consistency of new new data with a previously hypothesized model of stem cell regulation. Exp. Hematol. 17 (1989), 962-967.

[188] M. Loeffler, K. Pantel, H. Wulff, H. E. Wichmann, A mathematical model of erythropoiesis in mice and rats, Part 1. Structure of the model, Cell Tissue Kinet., 22 (1989), 13-30.

[189] M. Loeffler, K. Pantel, A mathematical model of erythropoiesis suggests an altered plasma volume control as cause for anemia in aged mice. Exp. Gerontology, 25 (1990), 483-495.

[190] M. Loeffler, I. Roeder. Tissue Stem Cells: definition, plasticity, heterogeneity, self organization and models - a conceptual approach. Cells Tissues Organs, 171 (1) (2002), 8-26.

[191] M. Loeffler, I. Roeder. Conceptual models to understand tissue stem cell organization. Current Opinion in Hematology, 11, (2004), 81-87.

[192] M. Loeffler, A. D. Tsodikov, A. Y. U. Yakolev, A cure model with time-changing risk factor: An application to the analysis of secondary leukemia. Statistics in Medicine, 17 (1998), 27-40.

[193] M.C. Mackey. Mathematical models of hematopoietic cell replication and control, pp. 149-178 in The Art of Mathematical Modelling: Case Studies in Ecology, Physiology and Biofluids (H.G. Othmer, F.R. Adler, M.A. Lewis, and J.C. Dallon eds.) Prentice Hall, 1997.

[194] M.C. Mackey. Cell kinetic status of hematopoietic stem cells. Cell Prolif., 34, (2001), 71-83.

[195] M.C. Mackey, U. an der Heiden. Dynamic diseases and bifurcations in physiological control systems, Funk. Biol. Med., 1 (1982), 156-164.

[196] M. C. Mackey, A.A.G. Aprikyan, D.C. Dale. The rate of apoptosis in post mitotic neutrophil precursors of normal and neutropenic humans. Cell Prolif.,, 36 (2003), 27-34.

[197] M.C. Mackey, P. Dörmer. Enigmatic hemopoiesis, in Biomathematics and Cell Kinetics (ed. M. Rotenberg), Elsevier/North Holland, (1981), 87-103.

[198] M. C. Mackey, L. Glass, Oscillation and chaos in physiological control systems. Science, 197 (1977), $287-289$.

[199] M.C. Mackey, P. Dörmer, Continuous maturation of proliferating erythroid precursors. Cell and Tissue Kinetics, 15, (1982), 381-392.

[200] M.C. Mackey, J. Milton. Feedback, delays, and the origins of blood cell dynamics. Comm. on Theor. Biol., 1 (1990), 299-327.

[201] M.C. Mackey, C. Ou, L. Pujo-Menjouet, J. Wu. Periodic oscillations of blood cell populations in chronic myelogenous leukemia. SIAM J. Math. Anal., 38(1), (2006), 166-187.

[202] M.C. Mackey, R. Rudnicki. Global stability in a delayed partial differential equation describing cellular replication. J. Math. Biol., 33 (1994), 89-109.

[203] M.C. Mackey, R. Rudnicki. A new criterion for the global stability of simultaneous cell replication and maturation processes. J. Math. Biol., 38 (1999), 195-219.

[204] J.M. Mahaffy, J. Bélair, M.C. Mackey. Hematopoietic model with moving boundary condition and state dependent delay. J. Theor. Biol., 190, (1998), 135-146.

[205] A. Marciniak-Czochra, A. D. Ho, W. Jäger T. Stiehl, W. Wagner. Modeling of asymmetric cell division in hematopoietic stem cells-regulation of self-renewal is essential for efficient repopulation. Stem Cells Dev., 18(3) (2009), $377-85$. doi: $10.1089 / \mathrm{scd} .2008 .0143$.

[206] A. Marciniak-Czochra, T. Stiehl, W. Wagner. Modeling of replicative senescence in hematopoietic development. Aging (Albany NY), 1 (8) (2009), 723-732.

[207] A. Marciniak-Czochra, T. Stiehl. Mathematical models of hematopoietic reconstitution after stem cell transplantation Model Based Parameter Estimation. Bock, H.G., Carraro, T., äger, W., Körkel, S., Rannacher, R., Schlöder, J.P., (Eds.) Contributions in Mathematical and Computational Sciences, Vol. 3, Springer Verlag, (2013), 191-206.

[208] A. Maximow. The Lymphocyte as a stem cell common to different blood elements in embryonic development and during the post-fetal life of mammals. Originally in German: Folia Haematologica 8. (1909), 125-134. (English translation: Cell Ther. Transplant.(2009),1:e.000032.01. doi:10.3205/ctt-2009-en-000032.01).

[209] D. Metcalf. The granulocyte-macrophage colony-stimulating factors. Science, (1985), 229(4708): $16-22$. doi:10.1126/science.2990035, PMID 2990035. 
[210] J. A. J. Metz, O. Diekmann, editors. The dynamics of physiologically structured populations, volume 68 of Lecture Notes in Biomathematics. Springer-Verlag, Berlin, 1986. Papers from the colloquium held in Amsterdam, 1983.

[211] P. Michel. Optimal Proliferation Rate in a Cell Division Model. Math. Model. Nat. Phenom. Vol. 1, No. 2, (2006),2344.

[212] F. Michor. Quantitative approaches to analyzing imatinib-treated chronic myeloid leukemia. Trends in Pharmacological. Sciences, 28 (2007), 197-199.

[213] F. Michor. Chronic myeloid leukemia blast crisis arises from progenitors. Stem Cells, 25 (2007), $1114-1118$.

[214] F. Michor. The long-term response to imatinib treatment of CML. British Journal of Cancer, 96 (2007), 679-680.

[215] F. Michor, T. P. Hughes, Y. Iwasa, S. Branford, N.P. Shah, C. L Sawyers, M. A. Nowak Dynamics of chronic myeloid leukemia. Nature, 435 (2005), 1267-1270.

[216] F. Michor, Y. Iwasa, M. A. Nowak. The age incidence of chronic myeloid leukemia can be explained by a one-mutation model. Proc. Natl. Acad. Sci. U S A (2006) 103, 14931-14934.

[217] J. Milton, M.C. Mackey. Periodic haematological diseases: Mystical entities or dynamical disorders?, J. Roy. Coll. Phys. (Lond) 23 (1989), 236-241.

[218] C. L. Mouser, E. S. Antoniou, J. Tadros, E. K. Vassiliou, A model of hematopoietic stem cell proliferation under the influence of a chemotherapeutic agent in combination with a hematopoietic inducing agent. Theoretical Biology and Medical Modelling (2014) 11:4 DOI: 10.1186/1742-4682-11-4.

[219] T. Niederberger, H. Failmezger, D. Uskat, D. Poron, I. Glauche, N. Scherf, I. Roeder, T. Schroeder, A. Tresch. Factor graph analysis of live cell imaging data reveals mechanisms of cell fate decisions. Bioinformatics (Oxford, England) (2015).

[220] W. Nijhof, H. Goris, B. Dontje, J. Dresz, M. Loeffler. Quantification of the cell kinetic effects of G-CSF using a model of human granulopoiesis, Experimental Hematology 21 (1993), 496 -501.

[221] G. C. Nooney. Iron kinetics and erythron development. Biophysical Journal, vol. 5, (1965), 755-765.

[222] I. Østby, L. S. Rusten, G. Kvalheim, P. Grøttum. A mathematical model for reconstitution of granulopoiesis after high dose chemotherapy with autologous stem cell transplantation. J. Math. Biol., 47(2) (2003), 101-36.

[223] I. Østby, R. Winther. Stability of a model of human granulopoiesis using continuous maturation. J. Math. Biol., 49(5) (2004), 501-36.

[224] H. Özbay, C. Bonnet, H. Benjelloun, J. Clairambault. Stability analysis of cell dynamics in leukemia. Mathematical Modelling of Natural Phenomena, 7(1) (2012), 203-234.

[225] K. Pantel, M. Loeffler, B. Bungart, H. E. Wichmann, A mathematical model of erythropoiesis in mice and rats. Part 4. Differences between bone marrow and spleen, Cell Tissue Kinet. 23 (1990), 283-297.

[226] J. F. Perez, C. P. Malta, C. P., F. A. B. Coutinho. Qualitative analysis of oscillations in isolated populations of flies. J. Theoret. Biol., 71 (1978), 505-514.

[227] J. Pimentel. Agent Based Model for the Production Mechanism and Control of Blood Cells in the Human Body. Proceedings of The National Conference On Undergraduate Research (NCUR), The University of North Carolina at Asheville, North Carolina, 2006.

[228] A. Plesa, G. Ciuperca V. Louvet, L. Pujo-Menjouet, S. Génieys, C. Dumontet, X. Thomas, V. Volpert. Diagnostics of the AML with immunophenotypical data. Math. Model. Nat. Phenom. Vol. 1, No. 2, (2006), 104-123.

[229] G. Prindull, B. Prindull, N. Meulen. Haematopoietic stem cells (CFUc) in human cord blood. Acta Paediatr Scand. 67(4) (1978), 413-6.

[230] L. Pujo-Menjouet, M. C. Mackey. Contribution to the study of periodic chronic myelogenous leukemia. Comptes Rendus Biologiques (2004), 327, 235-244.

[231] L. Pujo-Menjouet, S. Bernard, M.C. Mackey. Long period oscillations in a Go model of hematopoietic stem cells. SIAM J. Appl. Dyn. Sys., (2005), 4:312-332.

[232] H. Quastler. The analysis of cell population kinetics. Cell Proliferation, Ed. by L. T. Lanierton and R. J . M. Fry, p. 18. Blackwell Scientific Publications, Oxford (1963), 18-34.

[233] H. Quastler, F. G. Sherman. Cell population kinetics in the intestinal epithelium of the mouse. Exp Cell Res., Jun;17(3) (1959), 420-438.

[234] N. M. Rashidi, M. K. Scott, N. Scherf, A. Krinner, J. S. Kalchschmidt, K. Gounaris, M.E. Selkirk, I. Roeder, C. Lo Celso. In vivo time-lapse imaging of mouse bone marrow reveals differential niche engagement by quiescent and naturally activated hematopoietic stem cells. Blood, 124(1) (2014), 79-83.

[235] U. Reincke, M. Loeffler, H. E. Wichmann, B. Harrisson. The kinetics of granulopoiesis in long term mouse bone marrow culture. Part I. Int.J.Cell Cloning, 2 (1984), 394-407.

[236] C. Roberts, L. Kean, D. Archer, C. Balkan, L. L. Hsu. Murine and math models for the level of stable mixed chimerism to cure beta-thalassemia by nonmyeloablative bone marrow transplantation. Ann. N.Y. Acad. Sci. 1054 (2005), $423-8$.

[237] I. Roeder. Quantitative stem cell biology - Computational studies in the hematopoietic system. Curr. Opin. Hematol., 13 (4) (2006), 222-228.

[238] I. Roeder, K. Braesel, R. Lorenz, M. Loeffler. Stem cell fate analysis revisited: interpretation of individual clone dynamics in the light of a new paradigm of stem cell organization. Journal of biomedicine, biotechnology, (2007), 84656.

[239] I. Roeder, G. de Haan, C. Engel, W. Nijhof, B. Dontje, M. Loeffler. Interactions of Erythropoietin, Granulocyte Colony-Stimulating Factor, Stem Cell Factor, and Interleukin-11 on Murine Hematopoiesis During Simultaneous Administration, Blood, 919 (1998), 3222-3229. 
[240] I. Roeder I, M. d'Inverno. New experimental and theoretical investigations of hematopoietic stem cells and chronic myeloid leukemia. Blood cells, molecules and diseases 43 (2009), 88-97.

[241] I. Roeder, J. Galle, M. Loeffler. Theoretical concepts of tissue stem cell organization. Tissue Stem Cells, Edited by Christopher S . Potten, Robert B . Clarke, James Wilson, Andrew G . Renehan CRC Press (2006), 17-35.

[242] I. Roeder and I. Glauche. Towards an understanding of lineage specification in hematopoietic stem cells: A mathematical model for the interaction of transcription factors GATA-1 and PU.1. J. Theor. Biol., 2414 (2006), 852-865.

[243] I. Roeder, I. Glauche. Towards an understanding of lineage specification in hematopoietic stem cells: a mathematical model for the interaction of transcription factors GATA-1 and PU.1. Journal of theoretical biology, 241 (2006), 852-65.

[244] I. Roeder,I. Glauche Pathogenesis, treatment effects, and resistance dynamics in chronic myeloid leukemia-insights from mathematical model analyses. Journal of molecular medicine (Berlin, Germany), 86 (2008), 17-27.

[245] I. Roeder,M. Herberg,M. Horn. An "age"-structured model of hematopoietic stem cell organization with application to chronic myeloid leukemia. Bulletin of mathematical biology, 71 (2009), 602-26.

[246] I. Roeder, M. Kamminga, K. Braesel, B. Dontje, G. de Haan, M. Loeffler. Competitive clonal hematopoiesis in mouse chimeras explained by a stochastic model of stem cell organization. Blood, 152 (2005), 609-616.

[247] I. Roeder, M. Horn, I. Glauche, A. Hochhaus, M. C. Mueller, M. Loeffler. Dynamic modeling of imatinib-treated chronic myeloid leukemia: functional insights and clinical implications. Nature medicine, 12 (2006), 1181-4.

[248] I. Roeder, K. Horn, H. B. Sieburg, R. Cho, C. Muller-Sieburg, M. Loeffler. Characterization and quantification of clonal heterogeneity among hematopoietic stem cells: a model-based approach. Blood, 112 (2008), 4874-83

[249] I. Roeder, M. Loeffler. A Novel Dynamic Model of Hematopoietic Stem Cell Organization Based on the Concept of Within-Tissue Plasticity. Experimental Hematology, 30 (8) (2002), 853-861.

[250] I. Roeder, M. Loeffler, P. J. Quesenberry, G. A. Colvin, J. F. Lambert. Quantitative tissue stem cell modeling. Blood, 102 (3) (2003), 1143-1144.

[251] I. Roeder, R. Lorenz. Asymmetry of stem cell fate and the potential impact of the niche: observations, simulations, and interpretations. Stem cell reviews 2 (2006), 171-80.

[252] S. I. Rubinow. A Maturity-Time Representation for Cell Populations. Biophys J., Oct; 8(10) (1968), 1055-1073. doi: 10.1016/S0006-3495(68)86539-7

[253] S. I. Rubinow, J. L. Lebowitz. A mathematical model of neutrophil production and control in normal man. J. Math. Biol., 1 (1975), 187-225.

[254] R. Rudnicki. Global stability of a nonlinear model of cellular populations, J. Tech. Phys., 38 (1997), 333-336.

[255] R. Rudnicki. Chaoticity of the blood cell production system. Chaos, 19(4) (2009), 043112. doi: 10.1063/1.3258364.

[256] R. Rudnicki, K. Pichór. Asymptotic behaviour of Markov semigroups and applications to transport equations, Bull. Polish Acad. Sci. Math., 45 (1997), 379-397.

[257] A. Safarishahrbijari, A. Gaffari. Parameter identification of hematopoiesis mathematical model - periodic chronic myelogenous leukemia. Wspolczesna Onkol, 17 (1) (2013), 73-77, DOI: 10.5114/wo.2013.33778.

[258] E. Sánchez, O. Arino, M. Kimmel. Noncompact semigroups of operators generated by cell kinetics models, Differential Integral Equations, 4 (6) (1991), 1233-1249.

[259] M. Santillan, J.M. Mahaffy, J. Bélair, M.C. Mackey. Regulation of platelet production: The normal response to perturbation and cyclical platelet disease. J. theor. Biol., 206, (2000), 585-603.

[260] S. Scheding, M. Loeffler, V. Anselsetter, H. E. Wichmann. A mathematical approach to benzo[a]pyrene-induced hematotoxicity, Arch Toxicology, 66 (1992), 546-550.

[261] S.Schirm, C. Engel, M. Loeffler, M. Scholz. A biomathematical model of human erythropoiesis under erythropoietin and chemotherapy administration. PLOS ONE, Vol. 8 (6), (2013), e65630.

[262] S.Schirm, C. Engel, M. Loeffler, M. Scholz. A combined model of human erythropoiesis and granulopoiesis under growth factor and chemotherapy treatment. Theoretical Biology and Medical Modelling, 11, (2014), 24.

[263] S.Schirm, C. Engel, M. Loeffler, M. Scholz. Modelling chemotherapy effects on granulopoiesis. BMC Syst Biol., (2014) $8(1), 138$.

[264] S. Schmitz, M. Loeffler, J. B. Jones, R. D. Lange, H. E. Wichmann. Synchrony of marrow maturation as origin of cyclic hemopoiesis, Cell Tissue Kinet., 23 (1990), 425-441.

[265] S. Schmitz, H. Franke, M. Loeffler, H. E. Wichmann, V. Diehl. Reduced variance of bone-marrow transit time of granulopoiesis - a possible pathomechanism of human cyclic neutropenia. Cell Prolif., 27 (1994), 655-667.

[266] S. Schmitz, H. Franke, M. Loeffler, H. E. Wichmann, V. Diehl. Model analysis of the contrasting effects of GM-CSF and G-CSF treatment on peripheral blood neutrophils observed in three patients with childhood-onset cyclic neutropenia. British Journal of Hematology, 954 (1996), 616-625.

[267] M. Scholz, C. Engel, M. Loeffler. Modelling Human Granulopoiesis under Polychemotherapy with G-CSF Support. Journal of Mathematical Biology, 10.1007 (2004), 285-295.

[268] M. Scholz, C. Engel, M. Loeffler. Model-based design of chemotherapeutic regimens that account for heterogeneity in leucopoenia. British Journal of Haematology, 132 (2006), 723-735.

[269] M. Scholz, A. Gross, M. Loeffler A biomathematical model of human thrombopoiesis under chemotherapy. Journal of Theoretical Biology, Vol. 264 (2), (2010), 287-300.

[270] H. Schwegler, M.C. Mackey. Fluctuations in circulating cell numbers following chemotherapy or bone marrow transplant, J. Math. Biol., 32 (1994), 761-770.

[271] L. Sharney, L. R. Wasserman, L. Schwartz, D. Tendler. Multiple pool analysis as applied to erythro-kinetics. Ann. N. Y. Acad. Sci., 10108 (1963), 230-49. 
[272] E. Shochat, V. Rom-Kedar, L. A. Segel. G-CSF control of neutrophils dynamics in the blood. Bull Math Biol., 69(7) (2007), 2299-338.

[273] J. A. Smith, L. Martin. Do cells cycle?, Proc. Natl. Acad. Sci. USA, 70 (1973), 1263- 1267.

[274] T. Stiehl, N. Baran, A. D. Ho, A. Marciniak-Czochra. Clonal selection and therapy resistance in acute leukaemias: mathematical modelling explains different proliferation patterns at diagnosis and relapse. Journal of The Royal Society Interface, 11 (2014) (94), 20140079.

[275] T. Stiehl, N. Baran, A. D. Ho, A. Marciniak-Czochra. Cell division patterns in acute myeloid leukemia stem-like cells determine clinical course: a model to predict patient survival. Cancer research, 75 (6), (2015), 940-949.

[276] T. Stiehl, A. Marciniak-Czochra. Characterization of stem cells using mathematical models of multistage cell lineages. Mathematical and Computer Modelling, 53 (7), (2011), 1505-1517.

[277] T. Stiehl, A. Marciniak-Czochra. Mathematical modeling of leukemogenesis and cancer stem cell dynamics. Mathematical Modelling of Natural Phenomena, 7 (01) (2012), 166-202.

[278] A. Świerniak, J. Klamka. Local Controllability of Models of Combined Anticancer Therapy with Delays in Control. Math. Model. Nat. Phenom. (2014) Vol. 9, No. 4, 216-226 DOI: 10.1051/mmnp/20149413.

[279] J. Swinburne, M.C. Mackey. Cyclical thrombocytopenia: Characterization by spectral analysis and a review. J. Theor. Med. (2000), 2, 81-91.

[280] H. Talibi Alaoui, R. Yafia. Stability and Hopf bifurcation in an approachable haematopoietic stem cells model. Math Biosci. (2007) 206(2), 176-84.

[281] T. Tian, K. Smith-Miles. Mathematical modeling of GATA-switching for regulating the differentiation of hematopoietic stem cell. BMC Systems Biology (2014), 8(Suppl 1):S8 http://www.biomedcentral.com/1752-0509/8/S1/S8.

[282] J. E. Till, E. A. McCulloch, L. Siminovitch. A Stochastic Model of Stem Cell Proliferation, Based on the Growth of Spleen Colony-Forming Cells. Proceedings of the National Academy of Sciences of the United States of America, (1964), 15, Vol. 51, No. 1, 29-36.

[283] A. D. Tsodikov, D. Hasenclever, M. Loeffler. Regression with bounted outcome score: Evaluation of power by bootstrap and simulation in a chronic myelogenous leukemia clinical trial, Statistics in Medicine 17 (1998), 1909-1922.

[284] V. Vainstein, Y. Ginosar, M. Shoham, A. Ianovski A. Rabinovich, Y. Kogan, V. Selitser, Z. Agur. Improving Cancer Therapy by Doxorubicin and Granulocyte Colony-Stimulating Factor: Insights from a Computerized Model of Human Granulopoiesis Math. Model. Nat. Phenom. (2006), Vol. 1, No. 2, 70-80.

[285] H. von Foerster. (1959), Some remarks on changing populations. F. Stohlman, ed., The kinetics of cell proliferation, Grune and Stratton, New York, 1959), 382-407.

[286] G. F. Webb. Theory of nonlinear age-dependent population dynamics, volume 89 of Monographs and Textbooks in Pure and Applied Mathematics. Marcel Dekker Inc., New York, 1985.

[287] G. F. Webb. An operator-theoretic formulation of asynchronous exponential growth. Trans. Amer. Math. Soc., (1987) 303(2) 751-763.

[288] G. F. Webb. Semigroup methods in populations dynamics: Proliferating cell populations, Semigroup Theory and Applications, Lecture Notes in Pure and Applied Mathematics Series,Vol. 116, Marcel Dekker, New York, 1989, 441449.

[289] G. F. Webb. Asynchronous exponential growth in differential equations with homogeneous nonlinearities, Differential Equations in Banach Spaces, Lecture Notes in Pure and Applied Mathematics Series, Vol. 148, Marcel Dekker, New York, (1993), 225-233.

[290] G. F. Webb. Asynchronous exponential growth in differential equations with asymptotically homogeneous nonlinearities, Adv. Math. Sci. Appl., Vol. 3 (1994), 43-55.

[291] G. F. Webb. Periodic and chaotic behavior in structured models of cell population dynamics, Recent Developments in Evolution Equations, Pitman Res. Notes Math. Series. 324 (1995), 40-49.

[292] G. F. Webb. Structured population dynamics, Banach Center Publications, Polish Academy of Sciences, Institute of Mathematics, Mathematical Modelling of Population Dynamics, Vol. 63 (2004), 123-163.

[293] G. F. Webb. Population models structured by age, size, and spatial position, in Structured Population Models in Biology and Epidemiology. Lecture Notes in Mathematics, Vol. 1936, Springer-Verlag, Berlin-New York (2008), 1-49.

[294] Z. L. Whichard, C. A. Sarkar, M. Kimmel, S. J. Corey. Hematopoiesis and its disorders: a systems biology approach. Blood (2010) 115: 2339-2347 doi:10.1182/blood-2009-08-215798.

[295] H. E. Wichmann, M. Loeffler, Probability of self-renewal: Assumptions and limitations. A commentary. Blood Cells, 9, (1983), 475-483.

[296] H. E. Wichmann, M. Loeffler, U. Reincke, The kinetics of granulopoiesis in long term mouse bone marrow culture. Part II. Int.J.Cell Cloning, 2 (1984), 408-424.

[297] H. E. Wichmann, M. Loeffler, S. Schmitz, A concept of hemopoietic regulation and its biomathematical realisation. Blood Cells, 14 (1988), 411-429.

[298] H. E. Wichmann, M. Loeffler, K. Pantel, H. Wulff, A mathematical model of erythropoiesis in mice and rats. Part 2. Stimulated erythropoiesis. Cell Tissue Kinet., 22, (1989), 31-49.

[299] O. Wolkenhauer, C. Auffray, O. Brass, J. Clairambault, A. Deutsch, D. Drasdo, F. Gervasio, L. Preziosi, P. Maini, A. Marciniak-Czochra, C. Kossow, L. Kuepfer, K. Rateitschak, I. Ramis-Conde, B. Ribba, A. Schuppert, R.Smallwood, G. Stamatakos, F. Winter, H. Byrne. Enabling multiscale modeling in systems medicine. Genome Med (2014) 6, 3 pages.

[300] H. Wulff, H. E. Wichmann, M. Loeffler, K. Pantel, A mathematical model of erythropoiesis in mice and rats. Part 3. Suppressed erythropoiesis. Cell Tissue Kinet., 22 (1989), 51-61.

[301] C. Zhuge, J. Lei, M.C. Mackey. Neutrophil dynamics in response to chemotherapy and G-CSF. J. Theor. Biol. (2012) $293,111-120$. 